\title{
Tailoring Catalyst Morphology towards High Performance for Low Pt Loaded PEMFC Cathodes
}

\author{
Gregor S. Harzer, ®*,z Alin Orfanidi, Hany El-Sayed, Pankaj Madkikar, ${ }^{*}$ \\ and Hubert A. Gasteiger**
}

Chair of Technical Electrochemistry, Department of Chemistry and Catalysis Research Center, Technical University of Munich, D-85748 Garching, Germany

\begin{abstract}
The effect of the catalyst synthesis method on the location of platinum nanoparticles on a high surface area Ketjenblack is investigated with respect to the high current density performance in low loaded proton exchange membrane fuel cells (PEMFC). Catalysts were prepared using various synthetic methods to deposit platinum nanoparticles at different locations on the carbon surface, e.g. inside or outside the pores of the primary particle. Transmission electron microscopy (TEM) suggested, that the Pt-particle deposition can be controlled to be preferentially on the outer carbon surface or within the pores. Electrochemical characterization was performed in thin-film rotating disk electrode (RDE) setup as well as in $5 \mathrm{~cm}^{2}$ single cell MEA tests. Although the carbon support was identical for all catalysts, the one with more Pt particles deposited on the outer carbon surface performed superior at high current which was attributed to a lower oxygen mass transport resistance. From the presented data, it can be concluded that not only the type or the surface area of the carbon black support affects the fuel cell performance, but that the synthesis approach is an additional parameter to tune the fuel cell performance at high current density.

(C) The Author(s) 2018. Published by ECS. This is an open access article distributed under the terms of the Creative Commons Attribution 4.0 License (CC BY, http://creativecommons.org/licenses/by/4.0/), which permits unrestricted reuse of the work in any medium, provided the original work is properly cited. [DOI: 10.1149/2.0311810jes]

(cc) BY
\end{abstract}

Manuscript submitted April 4, 2018; revised manuscript received June 27, 2018. Published July 10, 2018. This was Paper 1572 presented at the National Harbor, Maryland Meeting of the Society, October 1-5, 2017.

One of the challenges for fuel cell electric vehicles (FCEVs) to become cost-competitive with internal combustion engines is the reduction of the platinum catalyst loading. As kinetics of the hydrogen oxidation in acidic media are fast, ${ }^{1}$ only little $\mathrm{Pt}$ is needed on the anode $\left(<0.1 \mathrm{mg}_{\mathrm{Pt}} / \mathrm{cm}_{\mathrm{MEA}}^{2}\right)$, while loadings of about $0.2-0.4 \mathrm{mg}_{\mathrm{Pt}} / \mathrm{cm}_{\mathrm{MEA}}^{2}$ are typically used on the cathode due to the sluggish ORR kinetics. A significant reduction of the cathode Pt loading to below $0.1 \mathrm{mg}_{\mathrm{Pt}} / \mathrm{cm}_{\mathrm{MEA}}^{2}$ is estimated to be necessary for a large scale commercialization of FCEVs with a total platinum loading of about $<10 \mathrm{~g}$ Pt per car in the future. .,3 $^{2,3}$

One possibility to reach this target is to increase the mass activity of $\mathrm{Pt}$ for the oxygen reduction reaction (ORR) by using Pt-alloy catalysts while simultaneously decreasing the overall Pt loading at the cathode of the membrane electrode assembly (MEA). Additionally, the FC-stack should be operated at high current density, i.e., at high power density, in order to keep the overall stack size and cost small. So far, conventional Pt-alloy nanoparticle supported on high-surface area carbons show $\approx 3-4$ times higher ORR activities when tested in RDE compared to actual proton exchange membrane (PEM) fuel cell test. ${ }^{4,2}$ Unfortunately, for more advanced ORR catalyst concepts like shape-controlled Pt-alloys ${ }^{5,6}$ and confined alloy nanoparticles ${ }^{7}$ which show substantially higher ORR activities in rotating disk electrode (RDE) experiments, it has not yet been possible to prepare MEAs with good high current density performance. ${ }^{4,8}$ Reasons for this may include the difficulty of preparing electrodes with suitable structure and homogeneous ionomer distribution.

In addition, the morphology of the carbon black catalyst support was shown to have a major influence on the high current density performance. Usually, better high current density performance is observed for low-surface area supports like Vulcan carbon compared to highsurface area supports like Ketjenblack, even though the latter show a higher ORR mass activity. ${ }^{9-12}$ A detailed study of the influence of the carbon black support was conducted by Park et al., ${ }^{13}$ who investigated four different carbon black supports with different porosity and surface area. They concluded that a carbon black with high surface area and porosity shows poor high current density performance because a lot of Pt nanoparticles are located inside the pores and therefore are poorly accessible to oxygen at high current densities, i.e., at high local oxygen fluxes. The best high current density performance was

\footnotetext{
*Electrochemical Society Student Member

**Electrochemical Society Fellow.

${ }^{\mathrm{z}}$ E-mail: gregor.harzer@tum.de
}

observed for a carbon black support with very low surface area and minimal porosity, for which the majority of Pt particles were located on the outer surface of the support. Their observations with regards to the location of Pt particles as a function of the carbon support morphology are consistent with previous findings. ${ }^{14}$

In the present work, we show that neither the surface area nor the porosity of the carbon black support influences the high current density performance, but that the location of the Pt particles on the support, i.e., on the outer surface or inside the pores is the governing factor. Two different types of catalysts were prepared on the same high surface area Ketjenblack (KB) carbon support by an incipient wetness and a polyol reduction process to control the location of $\mathrm{Pt}$ particle deposition. Additionally, the polyol reduction was used to prepare a catalyst on a surface-modified KB support (functionalized by $\mathrm{NH}_{\mathrm{x}}$ groups $)^{15}$ to investigate the effect of ionomer distribution in the catalyst layer. ORR mass activities obtained by RDE and fuel cell measurements as well as high current density performance under differential-flow conditions of the here synthesized catalysts were compared to a commercial catalyst on high surface area Ketjenblack (TEC10E20E, TKK).

\section{Experimental}

Carbon functionalization with $\mathrm{NH}_{x}$ surface groups $\boldsymbol{K B}\left(\boldsymbol{N} \boldsymbol{H}_{x}\right)$. - The preparation of surface modified carbon and the deposition of Pt nanoparticles were performed as previously described in detail. ${ }^{15}$ In short, commercially available Ketjenblack (E-type, Tanaka Kikinzoku Kogyo K.K., Japan) with a surface area of $930 \mathrm{~m}^{2} / \mathrm{g}$ (determined by QSDFT from $\mathrm{N}_{2}$ sorption) was dispersed in $100 \mathrm{ml}$ of $70 \% \mathrm{HNO}_{3}$ (Sigma Aldrich, ACS reagent) and stirred under reflux conditions $\left(70^{\circ} \mathrm{C}\right.$ oil bath) for $30 \mathrm{~min}$. After filtration, the carbon (further on referred to as "KB-Ox") was washed with hot water (from Milli-Q Integral System; $>15 \mathrm{M} \Omega \cdot \mathrm{cm}$ ) and dried in vacuo. Aminated Ketjenblack ("KB( $\mathrm{NH}_{\mathrm{x}}$ )") was prepared by placing $1 \mathrm{~g}$ of $\mathrm{KB}-\mathrm{Ox}$ in a tube furnace (HST12/400, Carbolite $\mathrm{GmbH}$, Germany) for $4 \mathrm{~h}$ at $200^{\circ} \mathrm{C}$ under pure $\mathrm{NH}_{3}$ gas with a flow rate of $1 \mathrm{l} / \mathrm{min}$. The carbon was washed with hot water and dried in a vacuum oven at $70^{\circ} \mathrm{C}$.

Synthesis of $20 \%{ }_{w t} \mathbf{P t} / \mathrm{KB}_{\mathrm{PO}}$ and $\mathrm{Pt} / \mathrm{KB}\left(\mathrm{NH}_{\boldsymbol{x}}\right)_{\mathbf{P O}}-300 \mathrm{mg}$ of carbon black, $200 \mathrm{ml}$ of ethylene glycol (Sigma Aldrich, ACS reagent), $100 \mathrm{ml}$ of $\mathrm{H}_{2} \mathrm{O}(>15 \mathrm{M} \Omega \cdot \mathrm{cm})$, and $1.54 \mathrm{ml}$ of $\mathrm{H}_{2} \mathrm{PtCl}_{6}(8 \mathrm{wt} \%$ $\mathrm{H}_{2} \mathrm{PtCl}_{6}$ in $\left.\mathrm{H}_{2} \mathrm{O} ; 0.25 \mathrm{~mol}_{\mathrm{Pt}} / \mathrm{l}\right)$ from Alfa Aesar; corresponding to $1.3 \mathrm{mmol}_{\mathrm{Pt}} / \mathrm{l}$ ) were stirred for $18 \mathrm{~h}$ at room temperature. The flask was transferred to a pre-heated oil bath at $120^{\circ} \mathrm{C}$ and stirred for $2 \mathrm{~h}$. The 
catalyst was separated by filtration, washed with hot water until the filtrate was $\mathrm{pH}$ neutral and chloride free and dried in a vacuum oven at $70^{\circ} \mathrm{C}$ for $12 \mathrm{~h}$. The final platinum loading was quantified by TGA.

Synthesis of $20 \%$ wt $\boldsymbol{P t} / \mathbf{K B}_{\boldsymbol{I W}} \cdot-\mathrm{H}_{2} \mathrm{PtCl}_{6} \cdot \mathrm{x} \mathrm{H}_{2} \mathrm{O}(\mathrm{x} \approx$ \% 6 ; Sigma Aldrich, $>99.9 \% \mathrm{tmb}, 0.2655 \mathrm{~g}$ ) was dissolved in $2.2 \mathrm{ml}$ acetone (Sigma Aldrich, Chromasolv; corresponding to $\approx 230 \mathrm{mmol}_{\mathrm{Pt}} / \mathrm{l}$ ) and added to $400 \mathrm{mg}$ Ketjenblack (dried in vacuum at $110^{\circ} \mathrm{C}$ ) to wet the entire carbon powder. The acetone was evaporated at $40^{\circ} \mathrm{C}$ under air in an oven. Then, the powder was finely ground and heated in $5 \% \mathrm{H}_{2} / \mathrm{Ar}(500 \mathrm{ml} / \mathrm{min})$ to $250^{\circ} \mathrm{C}$ for $30 \mathrm{~min}(10 \mathrm{~K} / \mathrm{min}$ heating rate) in a tube furnace (Carbolite). After cooling to room temperature under Ar flow, the gas was humidified by bubbling it through water at room temperature while air is slowly mixed into the Ar stream. This procedure was required to avoid catalysts ignition on removal from the tube furnace. The catalyst was then washed with hot water $(>15 \mathrm{M} \Omega \cdot \mathrm{cm})$ until the filtrate was $\mathrm{pH}$ neutral and chloride free and dried in vacuum at $70^{\circ} \mathrm{C}$. The final platinum loading was quantified by TGA.

Transmission electron microscopy.-Transmission electron microscopy (TEM) was used to determine the Pt particle size distribution and location on the carbon support. Electron microscopy samples were prepared by dispersing the catalyst in deionized water and then depositing a few drops of the suspension onto carbon-coated $\mathrm{Cu} 400$ TEM grids (Science Services, Germany). Imaging was performed using a Philips CM100 EM operated at $100 \mathrm{kV}$ at a resolution of $0.5 \mathrm{~nm}$. For the evaluation of the average Pt particle size distribution, $>400$ individual particles were measured using the software ImageJ (v. $1.51 \mathrm{j} 8)$.

Thermogravimetric analysis.-Thermogravimetric analysis (TGA) of the pure carbons (without platinum) was performed with a TGA/DSC 1 (Mettler Toledo, Switzerland) at a heating rate of $5 \mathrm{~K} / \mathrm{min}$ in argon to quantify the amount of functional groups on the pristine, oxidized, and aminated carbons. The Pt loading on carbon was evaluated by the weight loss upon burning the carbon in $67 \% \mathrm{O}_{2}$ in $\mathrm{Ar}$ at a heating rate of $25 \mathrm{~K} / \mathrm{min}$ to $1000^{\circ} \mathrm{C}$. The residual after the TGA ramp was verified to be pure Pt by XRD.

Elemental analysis.-CHNS analyses were performed using a EURO EA analyzer (Hekatech, Germany). Determination of the Pt content was done photometrically using a UV 160 photometer (Shimadzu, Japan).

$X$-ray photoelectron spectroscopy.-Surface chemical analysis was accomplished by X-ray photoelectron spectroscopy (Axis Supra, Kratos, UK). The powder samples were dispersed in water and dropcast onto a pre-cleaned copper foil, which was fixed to the sample holder. Subsequently, the sample was dried in ambient air followed by drying at $80^{\circ} \mathrm{C}$ in an oven. The spectra were recorded at a constant pass energy of $160 \mathrm{eV}$ and at a pressure below $5 \cdot 10^{-8}$ mbar.

Electrochemical characterization.-Experimental details on rotating disk electrode (RDE) measurements and fuel cell testing are given in our previous publications. ${ }^{15,16}$ In short, RDE inks were prepared by suspending the catalyst powder in DMF and drop-casting onto a polished $5 \mathrm{~mm}$ diameter GC electrode (Pine, USA) without the use of Nafion. All measurements were done at $25^{\circ} \mathrm{C}$ in $0.1 \mathrm{M} \mathrm{HClO}_{4}$ with gases being of 6.0 grade. Measured potentials are referenced to the reversible hydrogen electrode (RHE) scale and corrected for the iR drop.

Membrane electrode assemblies (MEA) with an active area of $5 \mathrm{~cm}^{2}$ were prepared by the decal transfer method. Catalyst inks were prepared by mixing the catalyst, water, 1-propanol and the ionomer dispersion (Asahi Kasei, Japan, $700 \mathrm{EW}$ ) in an $8 \mathrm{ml}$ HDPE bottle containing $5 \mathrm{~mm} \mathrm{ZrO}_{2}$ grinding media. The carbon content of the dispersion was adjusted from $20-30 \mathrm{mg}_{\mathrm{C}} / \mathrm{ml}_{\text {ink }}$ depending on the viscosity while the water content was fixed at $10 \%$ wt. The ionomer to
Table I. Elemental analysis (CHNS) of the carbon, hydrogen, oxygen, and sulfur content of the as-received Ketjenblack (KB), the oxidized Ketjenblack (KB-ox), and the Ketjenblack after the $\mathrm{NH}_{\mathrm{x}}$ functionalization $\left(\mathrm{KB}\left(\mathrm{NH}_{\mathbf{x}}\right)\right)$.

\begin{tabular}{lcccc} 
Sample & $\mathrm{C}\left[\%_{\mathrm{wt}}\right]$ & $\mathrm{H}\left[\%_{\mathrm{wt}}\right]$ & $\mathrm{N}\left[\%_{\mathrm{wt}}\right]$ & $\mathrm{S}\left[\%_{\mathrm{wt}}\right]$ \\
\hline $\mathrm{KB}$ & $95.9 \pm 0.0$ & $0.2 \pm 0.0$ & $0.1 \pm 0.0$ & 0.0 \\
$\mathrm{~KB}-\mathrm{ox}$ & $90.8 \pm 0.3$ & $0.3 \pm 0.1$ & $0.5 \pm 0.0$ & 0.0 \\
$\mathrm{~KB}\left(\mathrm{NH}_{\mathrm{X}}\right)$ & $94.9 \pm 1.1$ & $0.2 \pm 0.0$ & $1.1 \pm 0.1$ & 0.0
\end{tabular}

carbon ratio (I/C) was $0.65 \mathrm{~g} / \mathrm{g}$ for all electrodes. Anodes were prepared by the same procedure using a commercial Pt/V (TEC10V20E, TKK) catalyst. The MEAs were prepared by hot-pressing $5 \mathrm{~cm}^{2}$ anode and cathode decals at $155^{\circ} \mathrm{C}$ for 3 min to a $15 \mu \mathrm{m}$ thick membrane (Asahi Kasei). For each catalyst, two independent fuel cell measurements were conducted under differential-flow conditions using a $5 \mathrm{~cm}^{2}$ flow-field (see References 17 and 18), and the mean absolute deviation between both is shown as error bars in all figures (for more details on the fuel cell testing conditions see our previous publications). ${ }^{15,16}$

\section{Results and Discussion}

Characterization of carbon supports and catalysts.-Elemental analysis and X-ray photoelectron spectroscopy (XPS) was utilized to determine the bulk and surface composition of the Ketjenblack support before and after the functionalization procedure. Table I summarizes the carbon, hydrogen, nitrogen, and sulfur content of the as-received Ketjenblack (KB), after the oxidation with $\mathrm{HNO}_{3}(\mathrm{~KB}-\mathrm{ox})$, and after the $\mathrm{NH}_{\mathrm{x}}$ functionalization with ammonia $\left(\mathrm{KB}\left(\mathrm{NH}_{\mathrm{x}}\right)\right)$. In contrast to an untreated, low-surface area Vulcan carbon support, which has a carbon content of $\approx 99 \%$ wt , the carbon content of as-received Ketjenblack was only $\approx 96 \%_{\mathrm{wt}}$ (see Table I) due the presence of oxygen-containing surface groups on this high-surface area support (it is also noteworthy that in contrast to Vulcan carbon, no sulfur could be detected in $\mathrm{KB}$ carbon). ${ }^{15}$ Upon oxidation, the $\mathrm{N}$ content increased while the $\mathrm{C}$ content decreased (from 95.9 to $90.8 \%$ wt), which was caused by the formation of chemisorbed nitrogen oxides $\left(\approx 0.5 \%_{\mathrm{wt}}\right.$, see Table I) and the increase of oxygen functionalities on the surface. Chemisorbed nitrogen oxides were identified by XPS (see black line in Figure 1) at binding energies above $405 \mathrm{eV} .{ }^{19}$ After the ammonia treatment at

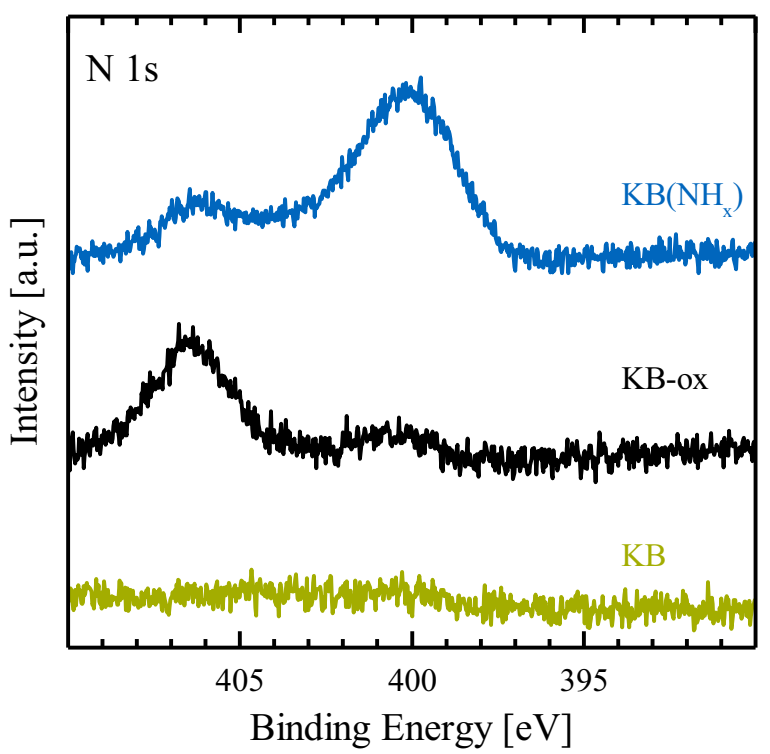

Figure 1. XP spectra in the $\mathrm{N} 1 \mathrm{~s}$ region of the as-received Ketjenblack (KB), the oxidized Ketjenblack (KB-ox), and the Ketjenblack after the $\mathrm{NH}_{\mathrm{X}}$ functionalization $\left(\mathrm{KB}\left(\mathrm{NH}_{\mathrm{x}}\right)\right)$. 


\begin{abstract}
Table II. Summary of results from rotating disk electrode experiments for the investigated catalysts in $0.1 \mathrm{M} \mathrm{HClO}_{4}$ at $25^{\circ} \mathrm{C}$. The $\mathrm{ECSA}$ was determined form the $\mathrm{H}_{\mathrm{UPD}}$ region in cyclic voltammetry $(20 \mathrm{mV} / \mathrm{s})$ or from the TEM based particle size distribution (using Equation 1), while the mass- and specific activity was determined from $\mathrm{O}_{2}$ saturated electrolyte at $1600 \mathrm{rpm}$ (anodic going scan, $20 \mathrm{mV} / \mathrm{s}$ ). The errors correspond to the standard deviation of 3 independent measurements.
\end{abstract}

\begin{tabular}{|c|c|c|c|c|c|c|}
\hline Catalyst & $\mathrm{Pt} / \mathrm{C}$ loading $\left[\%_{\mathrm{wt}}\right]$ & $E C S A_{H U P D}\left[\mathrm{~m}^{2} / \mathrm{g}_{\mathrm{Pt}}\right]$ & $E C S A_{\mathrm{TEM}}\left[\mathrm{m}^{2} / \mathrm{g}_{\mathrm{Pt}}\right]$ & $i_{0.9 \mathrm{~V}}^{\operatorname{mass}}[\mathrm{A} / \mathrm{g}]$ & $i_{0.9 \mathrm{~V}}^{\mathrm{spec}}\left[\mu \mathrm{A} / \mathrm{cm}_{\mathrm{Pt}}^{2}\right]$ & $\mathrm{TS}$ [mV/dec.] \\
\hline $\mathrm{Pt} / \mathrm{KB}_{\mathrm{PO}}$ & 20.2 & $75 \pm 6$ & 85 & $814 \pm 40$ & $1076 \pm 38$ & $57 \pm 2$ \\
\hline $\mathrm{Pt} / \mathrm{KB}\left(\mathrm{NH}_{\mathrm{x}}\right)_{\mathrm{PO}}$ & 20.3 & $79 \pm 7$ & 87 & $696 \pm 18$ & $878 \pm 24$ & $60 \pm 1$ \\
\hline $\mathrm{Pt} / \mathrm{KB}_{\mathrm{IW}}$ & 19.6 & $70 \pm 2$ & 90 & $336 \pm 7$ & $486 \pm 14$ & $64 \pm 2$ \\
\hline $\mathrm{Pt} / \mathrm{KB}_{\mathrm{TKK}}$ & 19.3 & $75 \pm 2$ & 99 & $982 \pm 13$ & $1305 \pm 27$ & $58 \pm 1$ \\
\hline
\end{tabular}

$200^{\circ} \mathrm{C}$, the carbon content increased again, which can be explained by the loss of thermally instable oxygen functional groups like carboxylic acid groups. ${ }^{20}$ Additionally, the nitrogen content increased further to about $1 \%_{\mathrm{wt}}$, and the XPS data (see blue line in Figure 1) indicates the formation of pyridinic, pyrrolic, and pyridine- $N$-oxide groups which were observed at binding energies of $397-404 \mathrm{eV} .{ }^{19}$ Further differentiation and quantification of each type of nitrogen functionality was not performed as it is beyond the scope of this work. However, from the $\mathrm{N}$-content determined by elemental analysis $(1.1 \pm 0.1 \%$, see Table I) and the external surface area of the modified Ketjenblack (total: $930 \mathrm{~m}^{2} / \mathrm{g}$; external: $\approx 400 \mathrm{~m}^{2} / \mathrm{g}$ ), an estimate of the ratio of surface nitrogen atoms to surface carbon atoms can be obtained, assuming a surface concentration of about $65 \mu \mathrm{mol}_{\mathrm{C}} / \mathrm{m}_{\mathrm{C}}^{2}$ (for graphite structures). ${ }^{21}$ For this estimation, the external surface area of Ketjenblack was used, as the pore-size analysis from $\mathrm{N}_{2}$ sorption and evaluation by the QSDFT method showed a blockage of small pores $(<4 \mathrm{~nm})$ by the surface modification, indicating that only the external surface was $\mathrm{NH}_{\mathrm{x}}$ modified. Based on the above assumptions, the ratio of suface nitrogen atoms to surface carbon atoms $\left(\mathrm{N}_{\text {surf }} / \mathrm{C}_{\text {surf }}\right)$ was in the range of 0.03 (or $3 \%$ of a monolayer coverage). Compared to the modification of vulcan carbon, where a coverage of about $7 \%$ was estimated, ${ }^{15}$ the lower coverage in the case of Ketjenblack might be due to a more limited accessibility of the entire carbon surface during the modification procedure or due to a lower reactivity of its surface. The platinum loading of each catalyst was determined by thermogravimetric analysis and is summarized in Table II. Generally, the Pt weight loading of all catalysts was within $20 \pm 1 \%_{\mathrm{wt}}$.

Transmission electron microscopy was used to evaluate the $\mathrm{Pt}$ particle size distribution and to gain insights into the location of the $\mathrm{Pt}$ particle location for the catalysts. Representative micrographs of the in-house made catalysts as well as the commercial catalyst are shown in Figure 2 with their corresponding Pt particle size distribution (insets in Figure 2). Here, $\mathrm{N}_{\text {total }}$ denotes the total number of counted particles, $d_{N}$ denotes the number averaged diameter, while $d_{S}$ is the surface normalized diameter calculated by Equation 1, where $l_{i}$ represents the particle number and $d$ its diameter.

$$
d_{S}=\frac{\sum_{i=1}^{n} l_{i} d^{3}}{\sum_{i=1}^{n} l_{i} d^{2}}
$$

For the catalysts prepared by the polyol reduction $\left(\mathrm{Pt} / \mathrm{KB}_{\mathrm{PO}}\right.$ and $\left.\mathrm{Pt} / \mathrm{KB}\left(\mathrm{NH}_{\mathrm{x}}\right)_{\mathrm{PO}}\right)$, a reasonably narrow distribution of $\mathrm{Pt}$ particles over the carbon surface was observed without major particle agglomeration (Figures $2 \mathrm{a}$ and $2 \mathrm{~b}$ ), and with similar number averaged particle sizes for the $\mathrm{Pt} / \mathrm{KB}\left(\mathrm{NH}_{\mathrm{x}}\right)_{\mathrm{PO}}$ catalyst $\left(\mathrm{d}_{\mathrm{N}}=3.0 \pm 0.5 \mathrm{~nm}\right)$ and the $\mathrm{Pt} / \mathrm{KB}_{\mathrm{PO}}$ catalyst $\left(\mathrm{d}_{\mathrm{N}}=2.9 \pm 0.7 \mathrm{~nm}\right)$. For the catalyst prepared by incipient wetness $\left(\mathrm{Pt} / \mathrm{KB}_{\mathrm{IW}}\right)$ and for the commercial catalyst $\left(\mathrm{Pt} / \mathrm{KB}_{\mathrm{TKK}}\right)$, the particle size distributions were slightly wider, while both have smaller number-averaged particle sizes of $d_{N}=2.2 \pm 0.9 \mathrm{~nm}$ and $\mathrm{d}_{\mathrm{N}}=2.4 \pm 0.7 \mathrm{~nm}$, respectively. Similarly, the surface averaged Pt particle sizes $\left(d_{S}\right)$ which should be inversely proportional to the electrochemically active surface area (ECSA) of the catalysts were also substantially smaller for the catalyst prepared by incipient wetness and for the commercial catalysts (see inset in Figure 2).

When comparing the TEM images obtained for the catalysts made by the polyol method to those obtained for the catalyst made by either the incipient wetness method or the commercial catalyst, differences in the Pt particle location can be discerned. In case of the polyol reduction (Figures $2 \mathrm{a}$ and $2 \mathrm{~b}$ ), many $\mathrm{Pt}$ particles were found on the edge of the carbon primary particle and not "inside" its projection (circles show examples in Figures $2 \mathrm{a}$ and $2 \mathrm{~b}$ ). Although TEM is a $2 \mathrm{D}$ technique, one can rationalize that when a Pt particle is observed outside of the carbon primary particle projection, then it must be located on the outside of the carbon particle. When it is within the projection of the carbon primary particle, then it can be either on top or inside the carbon primary particle in the respective image. Clearly, it is not possible to determine the amount of Pt particles inside the carbon primary particle, but rather get an estimate of particles located on or close to the outer surface. A more in depth study of Pt particle distribution by STEM (as used by Park et al. ${ }^{13}$ ) could unfortunately not be performed for this study, as we did not have access to this technique. Therefore, we could not quantify the Pt particle distribution on/inside the carbon support, but we believe that the here presented TEM images show at least qualitatively that the polyol synthesis results in catalysts with Pt particles deposited preferentially on the exterior surface of the carbon support.

Pt particles at the edge of the carbon support were hardly observed for the commercial catalyst and the one synthesized by the incipient wetness method. A detailed study on the platinum distribution on the primary carbon black particle via STEM analysis by Park et al. ${ }^{13}$ showed that about $62 \%$ of $\mathrm{Pt}$ particles are located within the carbon black for a commercial $30 \%_{\mathrm{wt}} \mathrm{Pt} / \mathrm{KB}$ catalyst (TEC10E30E, TKK), which is very similar to the commercial $20 \%_{\mathrm{wt}} \mathrm{Pt} / \mathrm{KB}$ catalyst used in this study (TEC10E20E, TKK). Based on the above study and the fact that almost no Pt particles were observed on the edge of the carbon black primary particles for both the commercial catalyst $\left(\mathrm{Pt} / \mathrm{KB}_{\mathrm{TKK}}\right)$ and the in-house made, incipient wetness based catalyst $\left(\mathrm{Pt} / \mathrm{KB}_{\mathrm{IW}}\right)$, it is reasonable to assume that the majority of the $\mathrm{Pt}$ particles for these two catalysts are also located inside the carbon particle. In contrast, the catalysts prepared by the polyol reduction method showed a significant amount of platinum particles on the edges of the carbon (examples marked by red circles in Figures $2 a$ and $2 b$ ), which suggests a considerable amount of Pt particles to be located on the outside of the carbon black. Based on these observations, a simplified sketch of the platinum particle distribution on the primary carbon black is proposed in Figures 2e and 2f. Although it is impossible to determine the precise three-dimensional distribution of platinum particles on the carbon black from 2D TEM images, a clear difference in catalyst morphology was evident when comparing the TEM images of the commercial catalyst and the catalyst prepared by incipient wetness (Figures $2 \mathrm{c}$ and $2 \mathrm{~d}$ ) to the catalysts prepared by the polyol reduction (Figures $2 \mathrm{a}$ and $2 \mathrm{~b}$ ). However, no relevant difference in morphology was observed in the TEM images for the Pt particles deposited on either as-received or $\mathrm{NH}_{\mathrm{x}}$ modified Ketjenblack by the polyol synthesis route. As will be shown later, the electrochemical activity and performance characteristics of the different catalysts are quite consistent with the differences in Pt location proposed in Figures $2 \mathrm{e}$ and $2 \mathrm{f}$.

The observed differences in Pt location of the in-house made catalysts all prepared on the same support must be due to the different synthetic procedures which are sketched in Figure 3. In the case of the polyol reduction, the platinum salt was dissolved at a rather low concentration $\left(1.3 \mathrm{mmol}_{\mathrm{Pt}} / \mathrm{l}\right)$ in ethylene glycol which served as the solvent and reducing agent. When the temperature was reached at which the reduction starts rapidly, nucleation of Pt particles will 

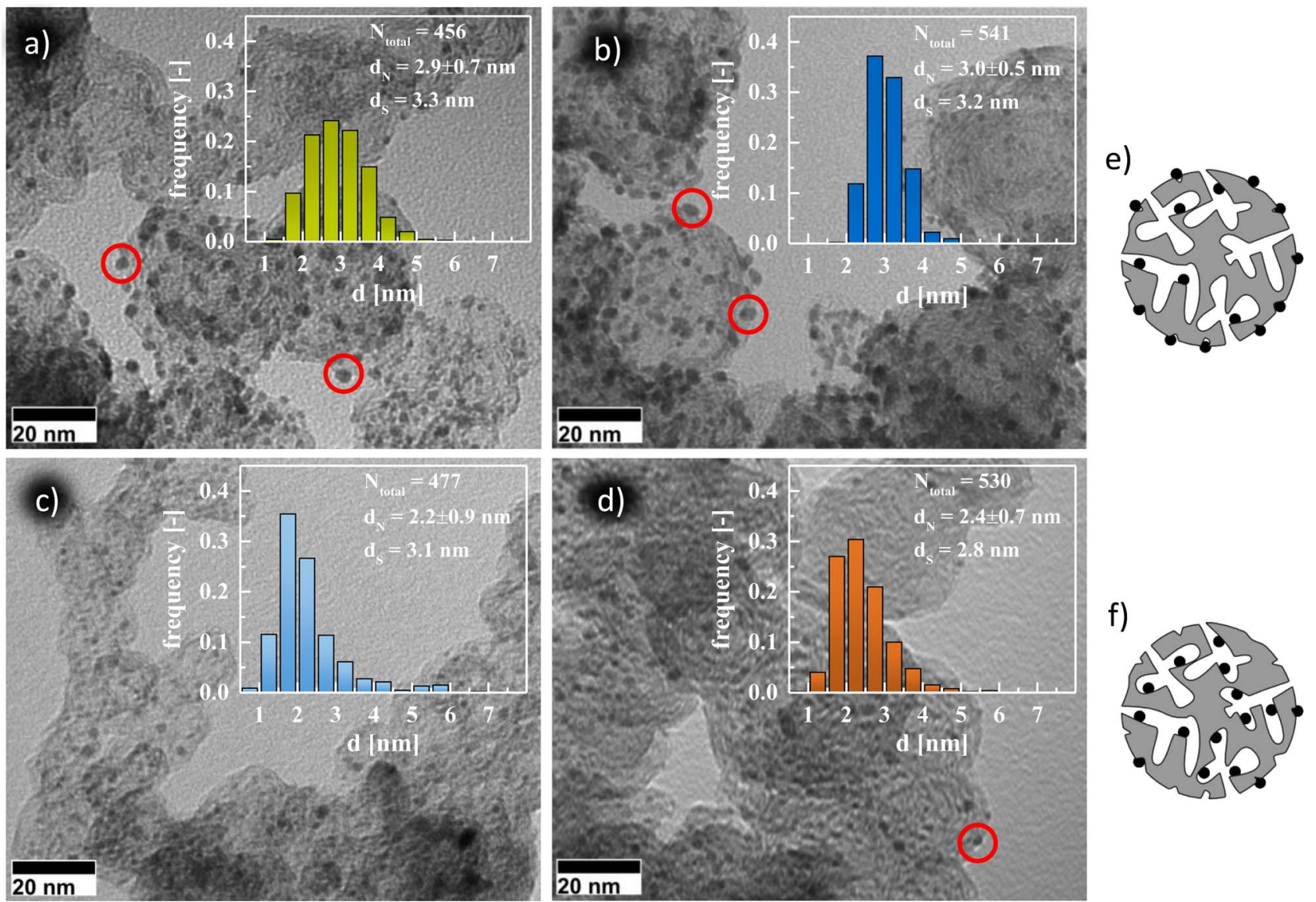

Figure 2. TEM micrographs and the corresponding particle size distribution for the various catalysts: (a) $\mathrm{Pt} / \mathrm{KB} \mathrm{PO}_{\mathrm{PO}}$ (b) $\mathrm{Pt} / \mathrm{KB}(\mathrm{NH})_{\mathrm{XO}}$; (c) $\mathrm{Pt} / \mathrm{KB} \mathrm{IW}_{\mathrm{IW}}$; and, (d) $\mathrm{Pt} / \mathrm{KB}_{\mathrm{TKK}} \cdot \mathrm{d}_{\mathrm{N}}$ denotes the number averaged diameter and their corresponding standard deviation, whereas $\mathrm{d}_{\mathrm{S}}$ denotes the surface normalized diameter calculated by Equation 1. Simplified schematic representation of primary carbon particle (gray) with Pt nanoparticles (black) deposited preferentially on (e) the outside of the carbon support (hypothesized to be the case for $\mathrm{Pt} / \mathrm{KB}_{\mathrm{PO}}$ and $\mathrm{Pt} / \mathrm{KB}\left(\mathrm{NH}_{\mathrm{x}}\right)_{\mathrm{PO}}$ ) and (f) on the inside of the carbon support (hypothesized to be the case for $\mathrm{Pt} / \mathrm{KB}$ IW and $\mathrm{Pt} / \mathrm{KB}_{\mathrm{TKK}}$ ).

occur throughout the solution, but since the concentration of platinum ions inside the pores of the carbon black was very small and since the platinum salt diffusion into the pores was restricted, growth of $\mathrm{Pt}$ particles proceeded preferentially on the outer surface of the carbon black and in the free bulk solution. Particles formed in solution will ultimately deposit on the outer surface as they cannot anymore pene-

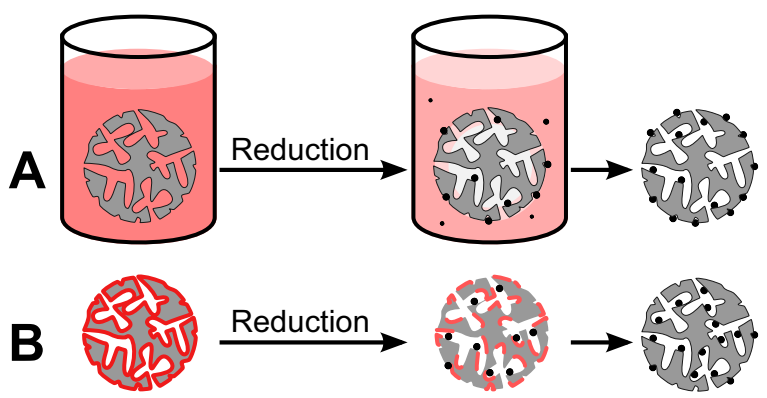

Figure 3. Simplified schematic representation of the synthetic methods and the time dependent formation of Pt particles; red color intensity depicts $\mathrm{Pt}$ precursor concentration. A) Reduction of a highly diluted Pt precursor in ethylene glycol in the polyol method, with a formation of Pt nanoparticles preferentially on the outside of the carbon surface and in the solution. B) Incipient wetness method, in which the carbon support is impregnated with a highly concentrated $\mathrm{Pt}$ precursor solution, so that a high concentration of $\mathrm{Pt}$ precursor is present inside the pores, leading to more particles deposited inside the carbon. trate into the pores of the carbon black (this is sketched in Figure 3A). On the other hand, in case of the incipient wetness synthesis, a highly concentrated solution of platinum ions $\left(\approx 230 \mathrm{mmol}_{\mathrm{Pt}} / \mathrm{l}\right)$ was absorbed into the void volume of the carbon black pores during impregnation. Upon reduction, platinum particles nucleated evenly on the entire carbon surface which was covered with the Pt salt (Figure 3B). As a substantial volume fraction of Ketjenblack consists of small pores (a lot of it being of course internal surface), ${ }^{10,22}$ which can be filled with the concentrated solution of platinum salt during impregnation, a considerable amount of Pt particles formed inside these pores similarly to what was observed for ordered mesoporous carbon supports with similar pore sizes. ${ }^{23,24}$

ECSA, ORR activity, and $\mathrm{H}_{2} / \mathrm{O}_{2} \mathrm{MEA}$ performance.-Thin-film rotating disk electrode measurements were conducted on all catalysts to determine the electrochemically active surface area (ECSA) and the activity for oxygen reduction. Catalyst thin-films were prepared without the use of any binder (like Nafion) to avoid catalyst poisoning and thus reveal the true ORR activities in the absence of poisoning by ionomer. ${ }^{25}$ Table II summarizes the results from RDE experiments for the investigated catalysts. The ECSA values obtained by cyclic voltammetry were rather similar for all catalyst, ranging between $\approx 70-79 \mathrm{~m}^{2} / \mathrm{g}_{\mathrm{Pt}}$. The fact that these values are roughly $10-25 \%$ lower than the values one would estimate from the TEM measurements $\left(E C S A_{T E M}\right)$ using Equation 1, is consistent with other literature reports. ${ }^{26}$ The obtained mass and specific activities were also in good agreement with the literature for Nafion-free films. ${ }^{25}$ Kinetic parameters of all catalysts are very comparable, except for $\mathrm{Pt} / \mathrm{KB}_{\mathrm{IW}}$ that 


\begin{abstract}
Table III. Cathode Pt loadings $\left(\mathrm{L}_{\mathrm{Pt}}\right)$ of the $\approx 20 \%$ wt $\mathrm{Pt} / \mathrm{KB}$ catalysts (s. Table II), electrochemically active surface areas $(E C S A)$ determined from the $\mathrm{H}_{\mathrm{UPD}}$ region in cyclic voltammetry, and ORR mass activity $\left(i_{0.9}^{\text {mass }}\right)$ determined at $0.9 \mathrm{~V}$ at the experimentally used conditions $\left(80^{\circ} \mathrm{C}, 100 \%\right.$ $\mathrm{RH}, \mathrm{H}_{2} / \mathrm{O}_{2}(2000 / 5000 \mathrm{nccm}), 170 \mathrm{kPa}$ abs $)$, calculated as well for $101 \mathrm{kPa}_{\mathrm{abs}} \mathrm{O}_{2}\left(i_{0.9}^{\text {mass }}{ }^{*}\right)$. The mass activity and Tafel slope (TS) were determined from the polarization curves after correction for the $H F R$, the proton conduction resistance in the catalyst layer, the $\mathrm{H}_{2}$ crossover, and the shorting current (these corrected data are shown in Figure $4 \mathrm{~b})$. The specific activity $\left(i_{0.9}^{\text {spec }}\right.$ ) was calculated from the mass activity and the corresponding $E C S A$ for each electrode. The variation represents the mean absolute deviation between two independent measurements.
\end{abstract}

\begin{tabular}{lccccc} 
Catalyst & $\mathrm{L}_{\mathrm{Pt}}\left[\mu \mathrm{g} / \mathrm{cm}_{\mathrm{geo}}^{2}\right]$ & $E C S A\left[\mathrm{~m}^{2} / \mathrm{g}_{\mathrm{Pt}}\right]$ & $i_{0.9 \mathrm{~V}}^{\text {mass }}[\mathrm{A} / \mathrm{g}]$ & $i_{0.9 \mathrm{~V}}^{\text {mass* }}[\mathrm{A} / \mathrm{g}]$ & $i_{0.9 \mathrm{~V}}^{\text {spec }}\left[\mu \mathrm{A} / \mathrm{cm}_{\mathrm{Pt}}^{2}\right]$ \\
\hline $\mathrm{Pt} / \mathrm{KB}_{\mathrm{PO}}$ & $62 \pm 1$ & $69 \pm 6$ & $220 \pm 11$ & $175 \pm 9$ & $318 \pm 11$ \\
$\mathrm{Pt} / \mathrm{KB}\left(\mathrm{NH}_{\mathrm{x}}\right)_{\mathrm{PO}}$ & $63 \pm 2$ & $66 \pm 2$ & $161 \pm 2$ & $128 \pm 1$ & $245 \pm 10$ \\
$\mathrm{Pt} / \mathrm{KB}_{\mathrm{IW}}$ & $64 \pm 1$ & $79 \pm 1$ & $249 \pm 1$ & $198 \pm 1$ & $76 \pm 1$ \\
$\mathrm{Pt} / \mathrm{KB}_{\mathrm{TKK}}$ & $62 \pm 2$ & $83 \pm 1$ & $372 \pm 29$ & $296 \pm 23$ & $46 \pm 1$ \\
& & & & $450 \pm 37$
\end{tabular}

has a slightly higher Tafel slope in addition to a lower ORR activity. Although the synthesis method used to prepare $\mathrm{Pt} / \mathrm{KB}_{\mathrm{IW}}$ was found to produce a catalyst with similar morphology as $\mathrm{Pt} / \mathrm{KB}_{\mathrm{TKK}}$ (determined by TEM), the catalytic properties of the former were significantly different from those of $\mathrm{Pt} / \mathrm{KB}_{\mathrm{TKK}}$. These differences in $\mathrm{RDE}$ results may arise from different catalyst layer quality on the glassy carbon, as high-quality film preparation was challenging for the $\mathrm{Pt} / \mathrm{KB}_{\mathrm{IW}}$ catalyst. This difficulty may be explained by a less polar catalyst surface, resulting from the heat-treatment in reductive atmosphere during the preparation of $\mathrm{Pt} / \mathrm{KB}_{\mathrm{IW}}$. Additional support to the hypothesis of low film quality is given by the fact that the ECSA is very similar for all catalyst, while only the ORR kinetic parameters are significantly worse. This observation has been directly attributed to a less homogeneous catalyst film by other researchers. ${ }^{27}$

$5 \mathrm{~cm}^{2}$ MEAs were fabricated to determine the influence of the catalyst preparation method on its specific properties like the ECSA, the ORR activity, and the performance at high current density in singlecell PEM fuel cell measurements. The cathode catalyst layers of all
MEAs had very similar loadings of $62-64 \mu \mathrm{g} / \mathrm{cm}_{\text {MEA }}^{2}$ to ensure comparability between measurements (for details see Table III), while the anode Pt loading was fixed at about $100 \mu \mathrm{g}_{\mathrm{Pt}} / \mathrm{cm}_{\mathrm{MEA}}^{2}$. The electrochemically active surface area determined from $\mathrm{H}_{\text {UPD }}$ for the $\mathrm{Pt} / \mathrm{KB}_{\mathrm{IW}}$ and $\mathrm{Pt} / \mathrm{KB}_{\text {TKK }}$ was found to be $\approx 79-83 \mathrm{~m}^{2} / \mathrm{g}_{\mathrm{Pt}}$ (see Table III). These values are consistent with previously reported values for high surface area carbon black supports. ${ }^{13,28,29}$ Significantly lower ECSA values of $\approx 66-69 \mathrm{~m}^{2} / \mathrm{g}_{\mathrm{Pt}}$ were found for the catalysts prepared by the polyol method. This is another indication that this synthesis method results in a larger fraction of $\mathrm{Pt}$ particles on the exterior surface of the carbon support particles, where they are in intimate contact with the ionomer resulting in lower ECSA values due to ionomer poisoning. ${ }^{25}$ The ORR mass activity trend with respect to the different catalyst preparation procedures which affect the location of the Pt particles on the primary carbon particle was also consistent with the observed ECSA trends: catalysts synthesized by the polyol method showed a lower ORR mass activity, consistent with the poisoning of the ORR when Pt nanoparticles are in more intimate contact with ionomer. ${ }^{25}$ Furthermore, the
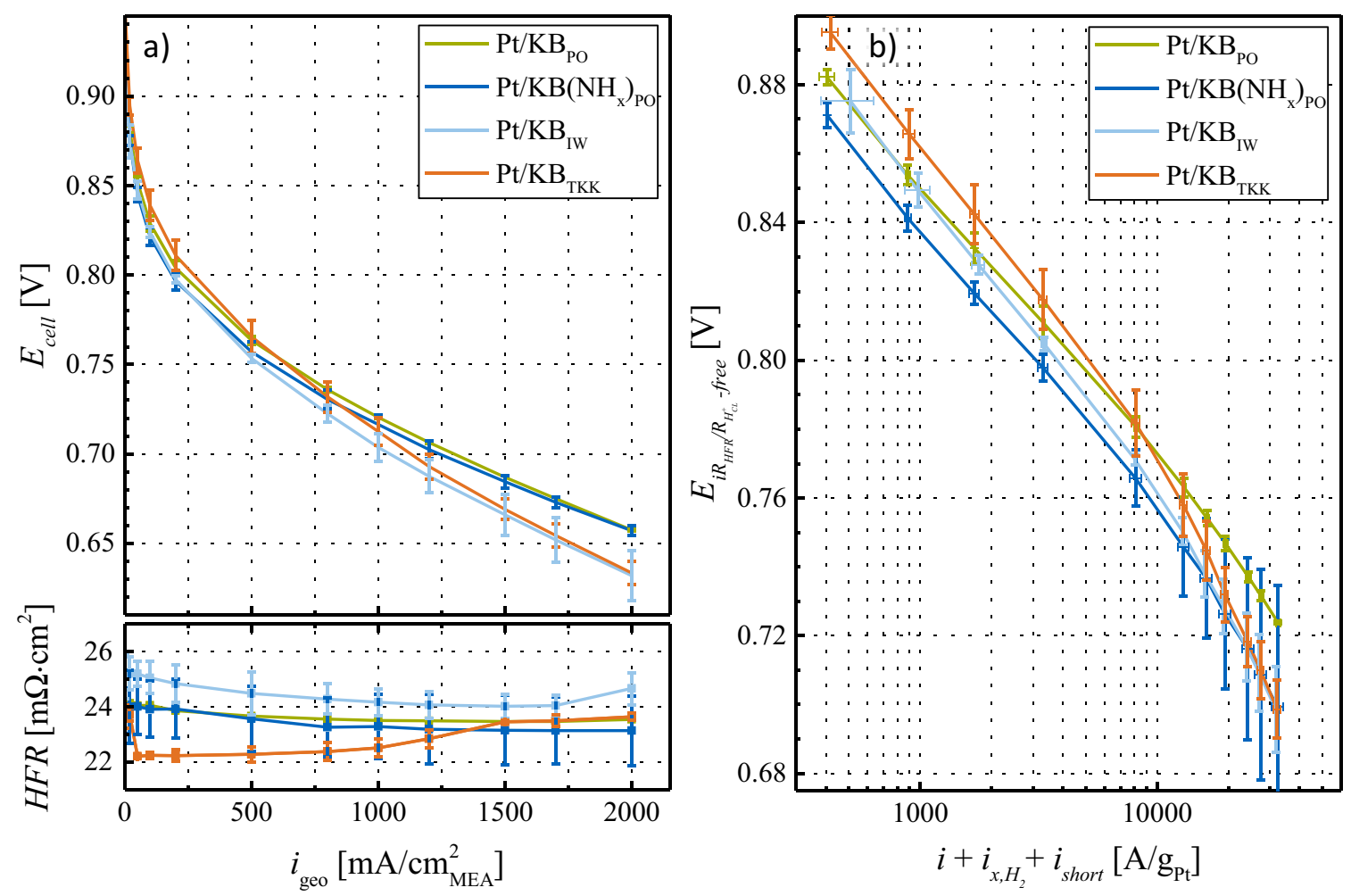

Figure 4. a) Uncorrected $\mathrm{H}_{2} / \mathrm{O}_{2}$ polarization curves $\left(80^{\circ} \mathrm{C}, 100 \% R H, \mathrm{H}_{2} / \mathrm{O}_{2}(2000 / 5000 \mathrm{nccm}), 170 \mathrm{kPa} \mathrm{abs}\right)$ for the different catalysts with ultra-low cathode Pt loading (62-64 $\mu \mathrm{g}_{\mathrm{Pt}} / \mathrm{cm}_{\mathrm{MEA}}^{2}$, see Table III) and the corresponding high frequency resistance $\left(R_{H F R}\right)$. b) Performance curves normalized to the Pt loading and corrected for the HFR $\left(R_{\mathrm{HFR}}\right)$, the effective proton conduction resistance of the cathode catalyst layer $\left(R_{H^{+}, \text {cath }}^{\text {eff }}\right)$ as well as $\mathrm{H}_{2}$ crossover $\left(i_{\mathrm{x}, \mathrm{H}_{2}}\right)$ and shorting currents. The anode platinum loading was $\approx 100 \mu \mathrm{g}_{\mathrm{Pt}} / \mathrm{cm}_{\mathrm{MEA}}^{2}$ for all MEAs. The error bars correspond to the mean absolute deviation between two independent measurements. 
low specific activity of the $\mathrm{Pt} / \mathrm{KB}\left(\mathrm{NH}_{\mathrm{x}}\right)_{\mathrm{PO}}$ catalyst $\left(245 \mu \mathrm{A} / \mathrm{cm}_{\mathrm{Pt}}^{2}\right.$; see Table III) was nearly as low as that of an identically prepared $\approx 20 \% \%_{\mathrm{wt}}$ $\mathrm{Pt}$ catalyst on a Vulcan support (see Pt/V-NH $\mathrm{NH}_{\mathrm{x}}$ with $200 \mu \mathrm{A} / \mathrm{cm}_{\mathrm{Pt}}^{2}$ in Ref. 15) tested under the same conditions and at the same I/C ratio, which provides further evidence for our claim that most of the Pt particles are deposited on the external KB carbon surface in the polyol synthesis process.

Figure 4 shows the uncorrected polarization curves in $\mathrm{H}_{2} / \mathrm{O}_{2}$ configuration at $170 \mathrm{kPa}_{\mathrm{abs}}$ for all catalysts (Figure 4a) as well as their corresponding Tafel plots after correction for the HFR, the effective proton conduction resistance of the cathode catalyst layer $\left(R_{H^{+}, \text {cath }}^{\text {eff }}\right)$ the $\mathrm{H}_{2}$-crossover $\left(\approx 4 \mathrm{~mA} / \mathrm{cm}_{\mathrm{MEA}}^{2}\right)$ and the shorting current (Figure $4 \mathrm{~b}$ ), analogous to the procedure outlined in Ref. 15. As platinum inside the pores of a carbon black primary particle has no or only poor contact with ionomer, ${ }^{30-32}$ it exhibits a higher mass activity due to the absence of poisoning effects. ${ }^{25}$ For this reason, $\mathrm{Pt} / \mathrm{KB}_{\mathrm{IW}}$ and $\mathrm{Pt} / \mathrm{KB}_{\mathrm{TKK}}$ showed a mass activity of $249 \pm 1$ and $372 \pm 29 \mathrm{~A} / \mathrm{g}$, while the $\mathrm{Pt} / \mathrm{KB}_{\mathrm{PO}}$ and $\mathrm{Pt} / \mathrm{KB}\left(\mathrm{NH}_{\mathrm{x}}\right)_{\mathrm{PO}}$ catalysts synthesized by the polyol method had lower mass activities of $220 \pm 11$ and $161 \pm 2 \mathrm{~A} / \mathrm{g}$, respectively. The lower mass activity of the latter most likely arises from a better ionomer distribution of the $\mathrm{KB}\left(\mathrm{NH}_{\mathrm{x}}\right)$ support as shown in a previous publication, ${ }^{15}$ where we argued that an increased interaction of the ionomer with the modified carbon black surface ${ }^{33}$ would lead to a more homogeneous ionomer distribution, reaching more platinum particles and thus lowering their ORR mass activity. In addition, part of this effect may also derive from a somewhat larger fraction of $\mathrm{Pt}$ being deposited on the outer surface of the $\mathrm{NH}_{\mathrm{x}}$-modified Ketjenblack due to a stronger Pt/support interaction during the deposition of Pt onto the surface-functionalized Ketjenblack. ${ }^{34}$ The difference in mass activity between $\mathrm{Pt} / \mathrm{KB}_{\mathrm{IW}}$ and $\mathrm{Pt} / \mathrm{KB}_{\mathrm{TKK}}$ could be rationalized by a non-optimized synthetic method for the incipient wetness based catalyst, which had the broadest particle size distribution and largest particles.

From the $\mathrm{H}_{2} / \mathrm{O}_{2}$ polarization curves, it is also evident that the different catalyst preparation methods lead to different performance characteristics in the low and high current density region (see Figure 4a): while the catalysts prepared by the polyol method showed a lower cell voltage in the low current density region (consistent with their lower mass activity), they significantly outperformed the $\mathrm{Pt} / \mathrm{KB}_{\mathrm{IW}}$ and $\mathrm{Pt} / \mathrm{KB}_{\mathrm{TKK}}$ catalysts at high current density. For the latter two, the polarization curves appeared to be affected by stronger mass transport resistances at high current density, even in pure oxygen. This limitation is also reflected in Figure 4b, where a substantial deviation from a straight Tafel line is observed for these catalysts at high current density, while the catalysts prepared by the polyol method did not deviate much from a straight line over the entire current density range. Additionally, their Tafel slope of $76 \mathrm{mV} / \mathrm{dec}$. (determined in the current density range of $50-500 \mathrm{~mA} / \mathrm{cm}_{\mathrm{MEA}}^{2}$; see Table III) was much closer to the expected value of $70 \mathrm{mV} / \mathrm{dec}$. (at $80^{\circ} \mathrm{C}$ ), ${ }^{35}$ indicating an optimized electrode where all non-kinetic limitations can be accounted for quantitatively. ${ }^{15}$ On the other hand, the higher Tafel slope of around $85 \mathrm{mV} / \mathrm{dec}$. for the $\mathrm{Pt} / \mathrm{KB}_{\text {IW }}$ and $\mathrm{Pt} / \mathrm{KB}_{\mathrm{TKK}}$ catalysts points toward a non-optimized electrode or additional transport losses. ${ }^{29}$ As will be explained in detail in the following, the electrode structure and ionomer distribution was homogeneous for all electrodes, so that we attribute the observed Tafel slope and performance limit at high current density to the catalyst morphology, namely the predominant location of $\mathrm{Pt}$ at the external surface of the carbon support or within the carbon nanopores.

The observed differences in mass activity and high current density performance have been commonly reported for Ketjenblack supported catalysts compared to Vulcan supported catalysts, and have been mainly attributed to differences in the support structure, especially support surface area and nanopore size distribution. ${ }^{13,12}$ As we used the same carbon support for all catalysts, it is clear that an additional factor which must be considered, is the synthesis method of the catalyst, as it is able to control the fraction of Pt particles which are deposited at the external support surface compared to those deposited within the carbon nanopores. Thus, even on a conventional

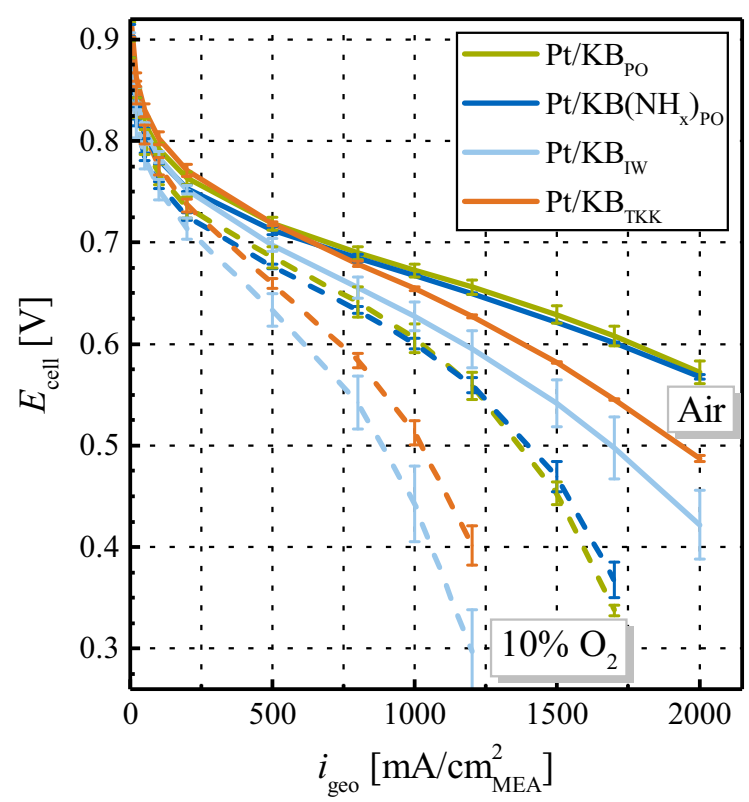

Figure 5. Polarization curves in air (solid lines) and $10 \% \mathrm{O}_{2}$ in $\mathrm{N}_{2}$ (dashed lines) at $80^{\circ} \mathrm{C}, 100 \% \mathrm{RH}, 2000 / 5000 \mathrm{nccm}(\mathrm{A} / \mathrm{C})$ at $170 \mathrm{kPa}_{\mathrm{abs}}$ for the different catalysts with a cathode loading of $62-64 \mu \mathrm{g}_{\mathrm{Pt}} / \mathrm{cm}_{\text {MEA }}^{2}$ (see Table III) and anode loadings of $\approx 100 \mu \mathrm{g}_{\mathrm{Pt}} / \mathrm{cm}_{\mathrm{MEA}}^{2}$. Error bars represent the mean absolute deviation from two independent measurements.

Ketjenblack support with a large nanopore volume, the polyol synthesis method can lead to a predominant deposition of Pt particles on the external carbon support surface, so that the resulting $\mathrm{Pt} / \mathrm{KB}$ catalyst shows a similar current-voltage profile as a catalyst supported on a more solid, Vulcan-type carbon. This finding is in excellent agreement with the studies from Kongkanand et al. ${ }^{11}$ They showed that the carbon support surface area (particularly the fraction of surface in micropores) and the location of the Pt particles on the primary carbon particles can significantly influence the local $\mathrm{O}_{2}$ mass transport resistance and in turn the performance of the MEA. Catalysts with Pt particles preferentially located on the outside of the carbon black support (Pt supported on a low surface area, solid carbon black, referred to as $\mathrm{GrC}$ ) showed significantly better performance at high current density compared to catalysts with Pt particles located inside the carbon black support (Pt supported on a high surface area carbon black, referred to as HSC). In a recent study they showed that by maximizing the nanopore volume of the support in the 4-7 nm range, the high current density performance can be further improved, rationalized by striking the best balance between reduced ionomer poisoning of Pt particles within these pores while minimizing the transport path length for protons and oxygen to these near surface pore domains. ${ }^{12}$

MEA performance with $\mathrm{H}_{2}$ /air and in $\mathrm{H}_{2} / 10 \% \mathrm{O}_{2}$.-To further visualize the high current density performance difference between catalysts prepared by the incipient wetness method and the polyol reduction method, polarization curves in air and $10 \% \mathrm{O}_{2}$ (in $\mathrm{N}_{2}$; to simulate conditions at the cathode outlet of a PEMFC stack operated at an air stoichiometry of $\approx 1.75$ ) are shown in Figure 5. Again, it was evident that the $\mathrm{Pt} / \mathrm{KB}_{\mathrm{TKK}}$ catalyst showed the highest cell voltage at low current density - consistent with its highest mass activity - while the high current density performance in air (solid lines in Figure 5) was significantly inferior to the catalysts prepared by the polyol method. This difference was even more pronounced for polarization curves in $10 \% \mathrm{O}_{2}$ (dashed lines in Figure 5), pointing toward a severe mass transport limitation for $\mathrm{Pt} / \mathrm{KB}_{\mathrm{IW}}$ and $\mathrm{Pt} / \mathrm{KB}_{\mathrm{TKK}}$ catalysts. As suggested by the TEM micrographs, a substantial fraction of $\mathrm{Pt}$ particles is located outside of the carbon black primary particle for the catalysts made by the polyol synthesis method (supported by the lower ORR 
activity of these catalysts). Assuming that the pores would be ionically connected with the ionomer by absorbed water, platinum particles which are not poisoned by ionomer can contribute to the ORR reaction at low current density, i.e., in the region where the mass activity is determined. At high current densities, however, the transport of reactants $\left(\mathrm{O}_{2}\right.$ and $\left.\mathrm{H}^{+}\right)$and the removal of produced water becomes increasingly important, resulting in increased transport resistances to platinum particles located inside the pores and, thus, to the poor high current density performance.

On the contrary, much superior high current density performance was observed for the catalysts synthesized by the polyol method: independent of the surface modification of the carbon black support, $\mathrm{Pt} / \mathrm{KB}_{\mathrm{PO}}$ and $\mathrm{Pt} / \mathrm{KB}\left(\mathrm{NH}_{\mathrm{x}}\right)_{\mathrm{PO}}$ showed almost identical current-voltage profiles. While the former had a $\approx 1.4$ times higher ORR mass activity (see Table III), its $\approx 10 \mathrm{mV}$ lower ORR overpotential (assuming an intrinsic Tafel slope of $70 \mathrm{mV} / \mathrm{dec}$.) did not play a major role at high current densities, where performance is controlled by transport resistances rather than by kinetics. It is also noteworthy that the $\mathrm{H}_{2}$ /air and $\mathrm{H}_{2} / 10 \% \mathrm{O}_{2}$ high current density performance of the polyol synthesized Ketjenblack supported catalysts was even slightly better than that of the polyol synthesized catalyst supported on $\mathrm{NH}_{\mathrm{x}}$ functionalized Vulcan carbon. ${ }^{15}$ Based on the evidence presented so far, we conclude that the superior high current density performance of the $\mathrm{Pt} / \mathrm{KB}_{\mathrm{PO}}$ and $\mathrm{Pt} / \mathrm{KB}\left(\mathrm{NH}_{\mathrm{x}}\right)_{\mathrm{PO}}$ catalysts in both air and $10 \%$ $\mathrm{O}_{2}$ is caused by a predominant deposition of platinum particles on the external surface of the carbon support in the polyol synthesis method. In summary, the inferior low current density and superior high current density performance of the polyol synthesized catalysts $\left(\mathrm{Pt} / \mathrm{KB}_{\mathrm{PO}}\right.$ and $\left.\mathrm{Pt} / \mathrm{KB}\left(\mathrm{NH}_{\mathrm{x}}\right)_{\mathrm{PO}}\right)$ reflects that of $\mathrm{Pt}$ catalysts supported on Vulcan supports, while that of the commercial and the incipient wetness synthesized catalysts $\left(\mathrm{Pt} / \mathrm{KB}_{\mathrm{TKK}}\right.$ and $\left.\mathrm{Pt} / \mathrm{KB}_{\mathrm{IW}}\right)$ reflects that of typical catalysts supported on Ketjenblack supports (see Figure $S 1$ in Ref. 12), again emphasizing that the synthesis method can affect the location of the deposited Pt particles and that this is not solely a function of the carbon support.

A general idea about the ionomer distribution in the electrodes can be deduced from proton resistivity measurements via impedance spectroscopy according to Liu et al. ${ }^{9}$ Figure 6 depicts the catalyst layer proton resistivity for all catalysts at different relative humidities. At high relative humidity $(100 \% R H)$, the difference in proton resistivity between all catalysts was insignificant, whereby it must be noted that the error of measurement was relatively large (reflected by the error bars), due to the difficulty of fitting a transmission line model to the impedance data when the proton conduction resistance is very

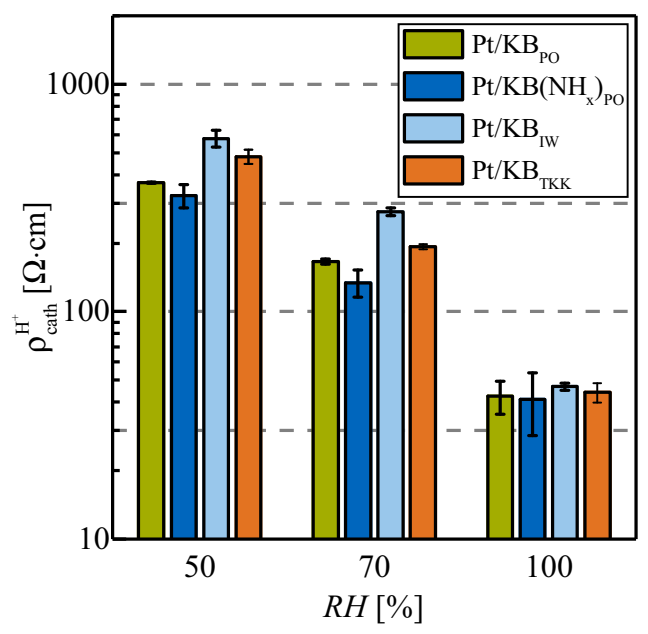

Figure 6. Cathode catalyst layer proton resistivity, $\rho_{\text {cath }}^{\mathrm{H}^{+}}$, determined from impedance spectroscopy at 50,70 and $100 \% R H$. Error bars represent the mean absolute deviation from two independent measurements.

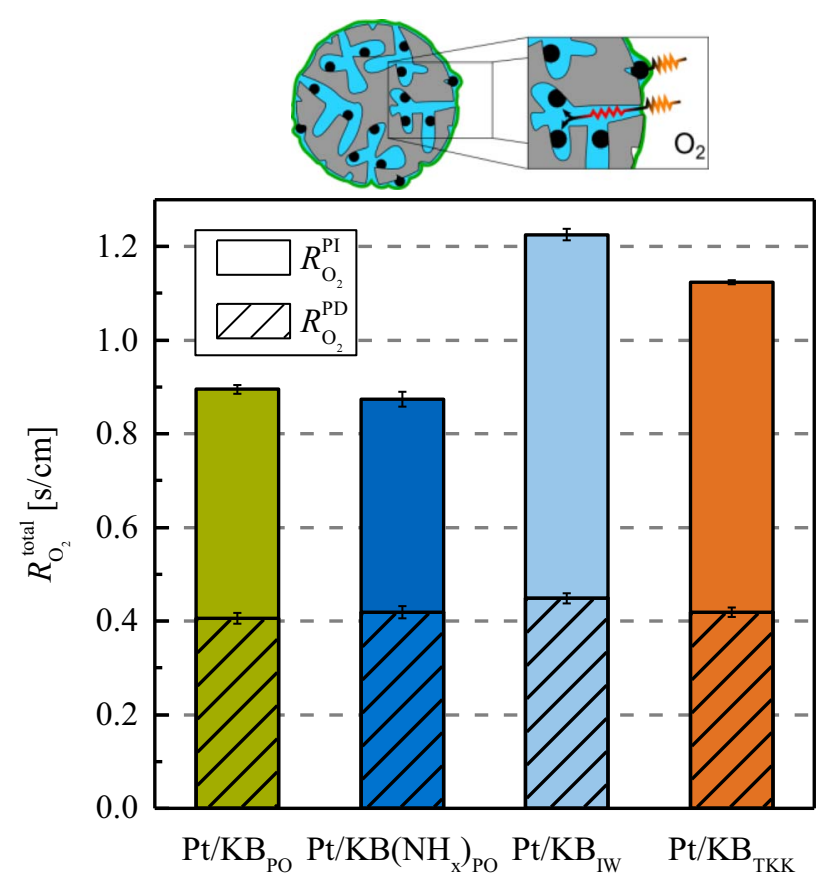

Figure 7. Total oxygen mass transport resistance divided into pressure dependent transport resistance $\left(R_{O_{2}}^{\mathrm{PD}}\right.$, hatched bar) and pressure independent transport resistance $\left(R_{O_{2}}^{\mathrm{PD}}\right.$, open bar) determined from limiting current measurements at $80^{\circ} \mathrm{C}, 70 \% R H$, differential-flow $(2000 / 5000 \mathrm{nccm})$ and 170,270 , $350,500 \mathrm{kPa}_{\mathrm{abs}}$ at various $\mathrm{O}_{2}$ concentrations. Simplified sketch depicting the different transport limitations depending on the location of the Pt particles on the carbon black support with additional resistance for the Pt particles inside the pore.

low. At lower relative humidities where the measurement error is reduced due to the larger proton conduction resistance, the catalysts prepared by the polyol reduction method showed $\mathrm{a} \approx 1.5-2$ times lower proton resistivity compared to $\mathrm{Pt} / \mathrm{KB}_{\mathrm{IW}}$ and $\mathrm{Pt} / \mathrm{KB}_{\mathrm{TKK}}$. This difference may point toward a better ionomer distribution for the catalysts prepared by the polyol synthesis method. Additionally, a beneficial effect on the proton resistivity was observed for the surface modification by $\mathrm{NH}_{\mathrm{x}}$ groups, which is consistent with our previous study on the modification of a Vulcan carbon support. ${ }^{15}$

Oxygen mass transport resistance.-To evaluate whether the observed performance drop at high current density can be attributed to oxygen mass transport, the total oxygen mass transport resistance is shown in Figure 7, divided into a pressure dependent, $R_{O_{2}}^{\mathrm{PD}}$ (hatched bar), and pressure independent, $R_{\mathrm{O}_{2}}^{\mathrm{PI}}$, resistance determined from limiting current measurements. ${ }^{36}$ According to the limiting current method developed by Baker et al., we used a low relative humidity of $70 \%$ $R H$ to avoid measurement artefacts due to condensation of water in the diffusion medium at high current density, ${ }^{36}$ similar to what was done by Owejan et al. ${ }^{37}$ In addition, we conducted the same limiting current experiments at $100 \% R H$ to exclude artefacts of insufficient proton conductivity at dry conditions. For all tested catalysts, no significant differences in total oxygen mass transport resistance were found at the two relative humidities ( $<5 \%$ deviation), indicating that neither proton conductivity nor water condensation in the GDL/MPL or the electrode were leading to measurement artefacts in the tested $R H$ range. Similar results were also obtained by $\mathrm{Oh}$ et al., who investigated the oxygen transport resistance from 30-90\% RH. ${ }^{38}$ Analogous with the works of Baker et al. ${ }^{36}$ and Owejan et al., ${ }^{37}$ we report the oxygen mass transport resistance determined at $70 \% \mathrm{RH}$ and use it later for the corrections of oxygen transport related voltage losses. 
As one would expect, the pressure dependent transport resistance, which is attributed to intermolecular gas diffusion, was essentially identical for all measurements, as the same testing hardware and GDL materials were used throughout the experiments. The pressure independent resistance however, which describes either Knudsen diffusion contributions in the microporous layer, diffusion through liquid water or through the $\mathrm{Pt} /$ ionomer interface, ${ }^{36,37}$ varied significantly for cathodes based on different types of catalysts. For the catalysts prepared by the polyol method, the total transport resistance was identical within the error of measurement $(0.88 \pm 0.02 \mathrm{~s} / \mathrm{cm})$, while $\mathrm{Pt} / \mathrm{KB}_{\mathrm{IW}}$ and $\mathrm{Pt} / \mathrm{KB}_{\mathrm{TKK}}$ showed considerably higher $R_{O_{2}}^{\text {total }}$ values $(1.22 \pm 0.01$ and $1.12 \pm 0.01 \mathrm{~s} / \mathrm{cm}$, respectively). In contrast to our previous study on the surface functionalization of a Vulcan carbon support with $\mathrm{NH}_{\mathrm{x}},{ }^{15}$ we found no significant influence of the $\mathrm{NH}_{\mathrm{x}}$ carbon surface modification on the mass transport resistance in the case of the here used Ketjenblack support at the same I/C mass ratio of $0.65 / 1$. The rationalization for this is that the ionomer film at this $\mathrm{I} / \mathrm{C}$ ratio is already very thin on the high surface area Ketjenblack support, as a significant fraction of the ionomer is being absorbed into the carbon nanopores $(\approx 60 \%$ for an I/C mass ratio of $\left.0.6 / 1^{9}\right)$. The resulting $\approx 1.7$ times thinner ionomer coverage on the outer surface of the Ketjenblack compared to the Vulcan carbon support may thus be so thin, that even a slightly inhomogeneous ionomer distribution on the carbon surface and/or in the electrode does not any more result in significant differences in the local oxygen transport resistance to the Pt surface.

In the case of $\mathrm{Pt} / \mathrm{KB}_{\mathrm{IW}}$ and $\mathrm{Pt} / \mathrm{KB}_{\mathrm{TKK}}$, the pressure independent oxygen mass transport resistance was substantially higher compared to the in-house made catalysts by the polyol reduction. Considering their morphological differences suggested by TEM and ORR mass activity measurements, these results clearly support our hypothesis for their inferior high current density performance, namely that it is due to the predominant location of Pt particles within the carbon black nanopores, leading to a higher oxygen transport resistance. ${ }^{11-13}$ The latter is ascribed to the long, local diffusion pathways for oxygen through the nanopores - particularly aggravated when nanopores are (partially) filled with liquid water (see sketch on top of Figure 7) - and manifests itself in additional voltage losses at high current density. On the other hand, when the platinum particles are preferentially located on the external surface of the support, either controlled by the synthetic method as shown here or by the type of carbon black support, ${ }^{11-13}$ the oxygen transport resistance is lower and, consequently, the performance at high current density is superior.

Voltage loss analysis.-To quantify the agreement between a kinetically predicted polarization curve and the measured $\mathrm{H}_{2} /$ air polarization curves (from Figure 5, solid lines) after correction for all known transport losses, a voltage loss analysis was performed as described in Ref. 15. Figure 8 shows the theoretical ORR curves (dashed lines; based on the mass activities given in Table III and assuming an intrinsic Tafel slope of $70 \mathrm{mV} / \mathrm{dec}$.) for all catalysts compared to $\mathrm{H}_{2}$ /air polarization curves after correction for all measurable losses (solid lines), namely for the ohmic losses (i.e., the $H F R$ ), the effective proton transport resistance within the electrode $\left(R_{\mathrm{H}^{+}, \text {cath }}^{\text {eff }}\right)$, and the total oxygen mass transport resistance $\left(R_{O}^{\text {total }}\right)$; for details see Ref. 15 . The lower graph in Figure 8 depicts the difference between the kinetically predicted ORR performance (dashed lines) and the measured $\mathrm{H}_{2} /$ air polarization curves after the above described corrections (solid lines), which is equal to the unaccounted voltage losses in the electrode. A striking difference between the two types of catalysts becomes evident. While the unaccounted voltage losses for the catalysts prepared by the polyol synthesis method $\left(\mathrm{Pt} / \mathrm{KB}_{\mathrm{PO}}\right.$ and $\left.\mathrm{Pt} / \mathrm{KB}\left(\mathrm{NH}_{\mathrm{x}}\right)_{\mathrm{PO}}\right)$ were identical and amount to $\approx 50 \mathrm{mV}$ at $2 \mathrm{~A} / \mathrm{cm}_{\mathrm{MEA}}^{2}$ (essentially identical to what we had found for a $\mathrm{Pt} / \mathrm{V}-\mathrm{NH}_{\mathrm{x}}$ catalyst ${ }^{15}$ ), the $\mathrm{Pt} / \mathrm{KB}_{\mathrm{IW}}$ and $\mathrm{Pt} / \mathrm{KB}_{\text {TKK }}$ catalyst showed unexplained voltage losses of about $200 \mathrm{mV}$ and $150 \mathrm{mV}$ at $2 \mathrm{~A} / \mathrm{cm}_{\mathrm{MEA}}^{2}$, respectively.

Thus, it is quite clear that catalysts with a large faction of $\mathrm{Pt}$ particles located on the external surface of the carbon black support $\left(\mathrm{Pt} / \mathrm{KB}_{\mathrm{PO}}\right.$ and $\left.\mathrm{Pt} / \mathrm{KB}\left(\mathrm{NH}_{\mathrm{x}}\right)_{\mathrm{PO}}\right)$ show low unaccounted voltage losses

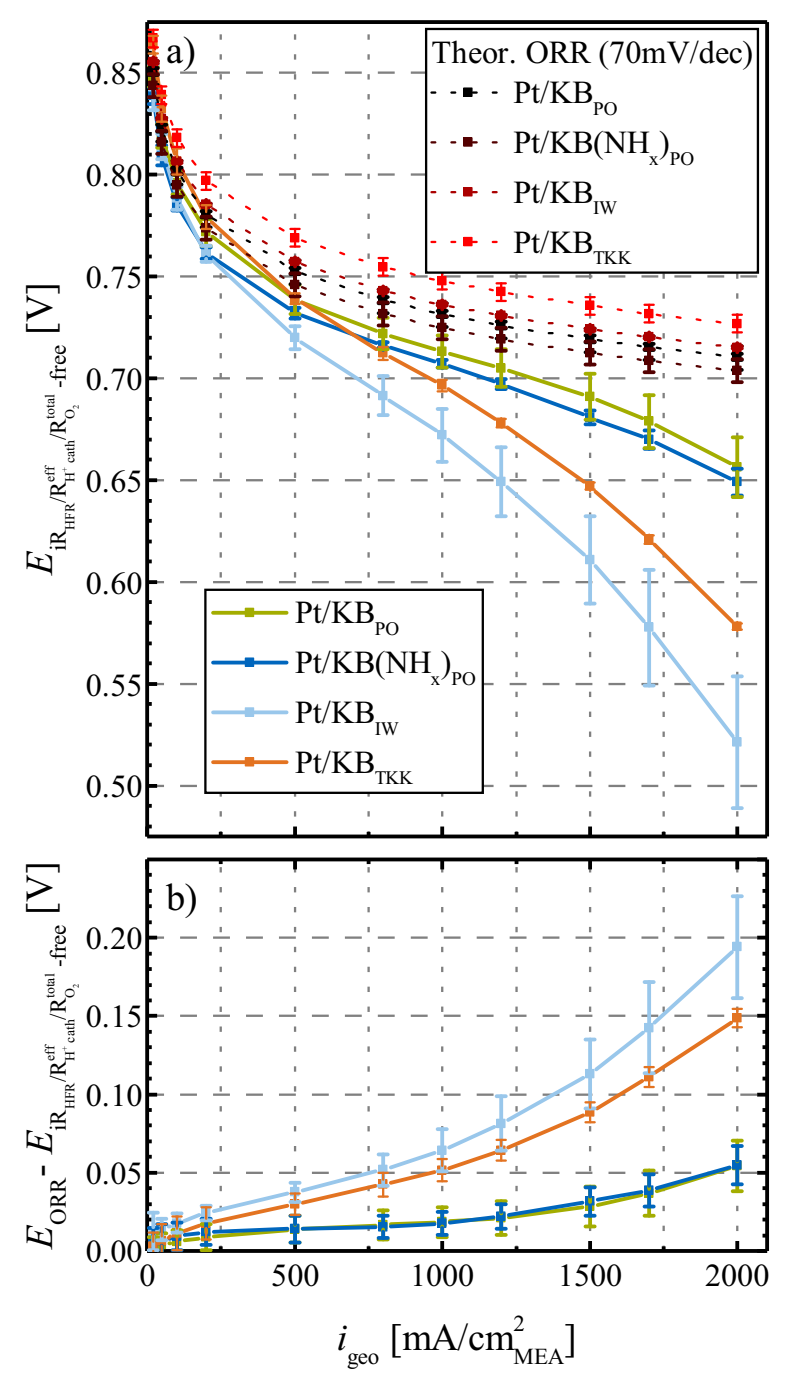

Figure 8. a) solid lines: polarization curves $\left(\mathrm{H}_{2} /\right.$ air - differential-flow, $80^{\circ} \mathrm{C}$, $\left.100 \% R H, 170 \mathrm{kPa}_{\mathrm{abs}}\right)$ corrected by the $H F R\left(R_{\mathrm{HFR}}\right)$, the effective proton conduction resistance of the catalyst layer $\left(R_{H^{+}, \text {cath }}^{\text {eff }}\right)$, and the total oxygen mass transport resistance $\left(R_{\mathrm{O}_{2}}^{\text {total }}\right)$; dotted lines: purely ORR kinetics limited polarization curves (black/red lines) determined from Equation 5 in Ref. 15 for the effective $\mathrm{O}_{2}$ partial pressure of $25.8 \mathrm{kPa}$ under these conditions. b) Unaccounted voltage losses obtained from the difference between the purely ORR kinetics limited performance (dotted lines in a) and the fully corrected $\mathrm{H}_{2} /$ air polarization curves (solid lines in a) for $\mathrm{Pt} / \mathrm{KB}_{\mathrm{PO}}, \mathrm{Pt} / \mathrm{KB}\left(\mathrm{NH}_{\mathrm{x}}\right)_{\mathrm{PO}}, \mathrm{Pt} / \mathrm{KB}_{\mathrm{IW}}$, and $\mathrm{Pt} / \mathrm{KB}_{\mathrm{TKK}}$.

in addition to their superior high current density $\mathrm{H}_{2} /$ air performance. This demonstrates that the morphology of the carbon black is not the only factor which controls high current density performance (as in previous studies), ${ }^{11-13}$ as long as the catalyst synthesis method leads to a preferential deposition of Pt particles on the external surface of the carbon black. Unfortunately, this analysis also makes it evident that the extent of unaccounted voltage losses (Figure 8b) in a cathode catalyst layer critically depends on the type of catalyst and is never zero. The origin of this discrepancy is not clear, but it seems reasonable to assume that it is at least in part related to an inherent problem of the determination of the oxygen mass transport resistance by limiting current measurements for high surface area carbons, where platinum is found inside the pores. While it cannot be excluded that the unaccounted voltage losses originate from a not fully optimized electrode or from more complex ORR kinetics, ${ }^{39}$ the inaccurate determination of the oxygen mass transport resistance appears to be the most likely explanation. 


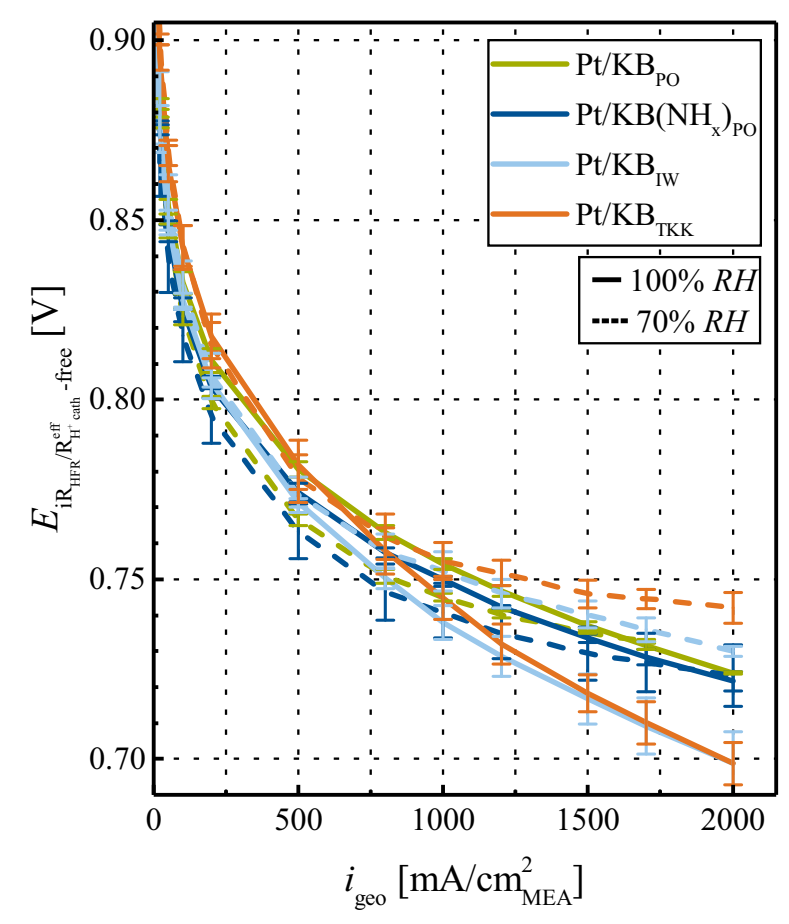

Figure 9. Differential-flow polarization curves in $\mathrm{H}_{2} / \mathrm{O}_{2}$ at $170 \mathrm{kPa}_{\mathrm{abs}}, 80^{\circ} \mathrm{C}$, $100 \% R H$ (solid lines) and $70 \% R H$ (dashed lines) after correction of the measured cell voltage by the HFR $\left(R_{\mathrm{HFR}}\right)$ and catalyst layer effective proton conduction resistance $\left(R_{H^{+}, \text {cath }}^{\text {eff }}\right)$. Error bars correspond to the mean absolute deviation from two independent measurements.

Identification of performance limitations.-To gain further insights into the mass transport properties of the different types of catalysts, we investigated the effect of the relative humidity on performance, first with pure $\mathrm{O}_{2}$ and then with $10 \% \mathrm{O}_{2}$ in $\mathrm{N}_{2}$. First of all, when reducing the relative humidity from $100 \%$ to $70 \%$, the $H F R$ increases by $\approx 10 \mathrm{~m} \Omega \cdot \mathrm{cm}^{2}$ (from about $23-25 \mathrm{~m} \Omega \cdot \mathrm{cm}^{2}$ at $100 \% R H$ (see lower panel of Figure 4 a) to $32-35 \mathrm{~m} \Omega \cdot \mathrm{cm}^{2}$ at $70 \% R H$ ), which equates to approximately a doubling of the membrane resistance for the typical contact resistance of $15 \mathrm{~m} \Omega \cdot \mathrm{cm}^{2}$ in our setup. This $\approx 2$-fold increase in membrane resistance is in good agreement with the reported changes of the bulk conductivity of a Nafion type membrane upon decreasing the relative humidity from $100 \%$ to $70 \% \mathrm{RH}^{40}$ At the same time, the proton sheet resistivity in the cathode catalyst layer increased by $\approx 3$-fold for the polyol synthesized catalysts and $\approx 5-7$ fold for the other two catalysts (see Figure 6), reasonably consistent with the reported ionomer tortuosity of $\approx 2-3$ in an electrode composed of a Ketjenblack supported catalyst and with an ionomer volume fraction of $\varepsilon_{\text {ionomer }} \approx 0.16$ (based on Equation 5 and Figure $9 \mathrm{a}$ in Ref. 41).

Figure 9 shows the $H F R$ and $R_{H^{+} \text {,cath }}^{\text {eff }}$ corrected differential-flow oxygen polarization curves recorded at $100 \%$ (solid lines) and $70 \%$ $R H$ (dashed lines) for all catalysts. $\mathrm{H}_{2} / \mathrm{O}_{2}$ polarization curves corrected this way would be expected to yield superimposing lines for both 70 and $100 \% R H$, as the oxygen transport resistance in the absence of strong film diffusion resistances through a water or ionomer layer should be negligible in pure $\mathrm{O}_{2}$. Within an error of $\approx 10 \mathrm{mV}$, this was indeed the case for the polyol synthesized catalysts (compare solid/dashed dark blue or green lines in Figure 9), where Pt particles are believed to be mostly located on the external carbon surface. However, for the $\mathrm{Pt} / \mathrm{KB}_{\mathrm{IW}}$ and $\mathrm{Pt} / \mathrm{KB}_{\mathrm{TKK}}$ catalysts (orange and light blue lines in Figure 9) with Pt particles mostly located in carbon nanopores, the corrected cell voltage increased with decreasing $R H$ by $\approx 35$ and $\approx 45 \mathrm{mV}$, respectively. This can be rationalized by a significant oxygen transport resistance from the exterior carbon surface to the Pt particles located in carbon nanopores, assuming that at $100 \%$

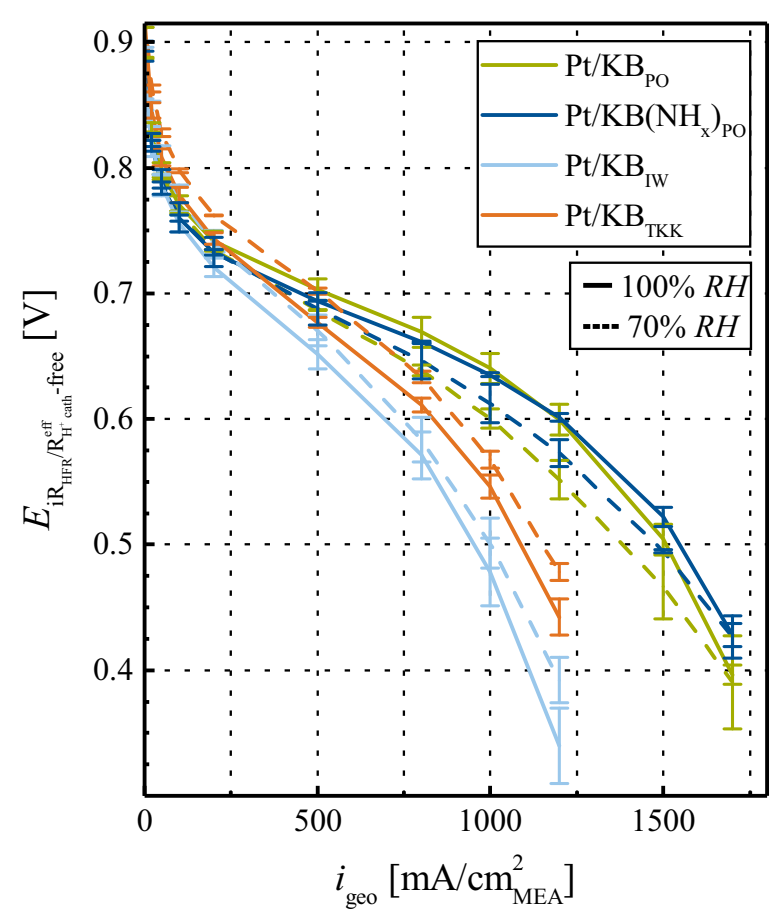

Figure 10. Differential-flow polarization curves in $\mathrm{H}_{2} / 10 \% \mathrm{O}_{2}$ (balance $\mathrm{N}_{2}$ ) at $80^{\circ} \mathrm{C}, 170 \mathrm{kPa}_{\mathrm{abs}}, 100 \% R H$ (solid lines) and $70 \% R H$ (dashed lines) for all catalysts after correction of the cell voltage by the HFR $\left(R_{\mathrm{HFR}}\right)$ and catalyst layer effective proton conduction resistance $\left(R_{H^{+}, \text {cath }}^{\text {eff }}\right)$. Error bars correspond to the mean absolute deviation of two independent measurements.

$R H$ these pores are flooded with liquid water, but at $70 \% R H$ have a lower water content and a concomitantly lower local oxygen transport resistance. This indeed is consistent with the observed inferior high current density performance of the $\mathrm{Pt} / \mathrm{KB}_{\mathrm{IW}}$ and $\mathrm{Pt} / \mathrm{KB}_{\mathrm{TKK}}$ catalysts in pure $\mathrm{O}_{2}$ compared to that of the $\mathrm{Pt} / \mathrm{KB}_{\mathrm{PO}}$ and $\mathrm{Pt} / \mathrm{KB}\left(\mathrm{NH}_{\mathrm{x}}\right)_{\mathrm{PO}}$ catalysts (see Figure 4a).

To identify the interplay of $\mathrm{O}_{2}$ mass transport resistance phenomena and relative humidity, differential-flow polarization curves in $\mathrm{H}_{2} / 10 \% \mathrm{O}_{2}$ (balance $\mathrm{N}_{2}$ ) were recorded at $70 \%$ and $100 \% \mathrm{RH}$ and are shown in Figure 10 after the correction of cell voltage by the HFR $\left(R_{\mathrm{HFR}}\right)$ and the effective proton conduction resistance in the catalyst layer $\left(R_{H^{+}, \text {cath }}^{\text {eff }}\right)$. In contrast to the data shown in Figure 9, the $\mathrm{O}_{2}$ transport resistance is very important at $10 \% \mathrm{O}_{2}$ (see Figure 5) and thus enables further insight into transport-related phenomena of the different catalysts.

Analogous to the phenomenon observed in pure $\mathrm{O}_{2}$, both the $\mathrm{Pt} / \mathrm{KB}_{\mathrm{IW}}$ and the $\mathrm{Pt} / \mathrm{KB}_{\mathrm{TKK}}$ catalysts showed a similar increase in the $H F R$ and $R_{H^{+} \text {,cath }}^{\text {eff }}$ corrected performance as the relative humidity is reduced from 100 to $70 \%$ (see Figure 10). This again was consistent with the above proposed decrease of the local oxygen transport resistance to Pt located in nanopores as the relative humidity is decreased.

On the other hand, the corrected cell voltage in $10 \% \mathrm{O}_{2}$ of the $\mathrm{Pt} / \mathrm{KB}_{\mathrm{PO}}$ and $\mathrm{Pt} / \mathrm{KB}\left(\mathrm{NH}_{\mathrm{x}}\right)_{\mathrm{PO}}$ catalyst based MEAs clearly decreased with decreasing $R H$ (see Figure 10), which is contrary to what was observed with pure $\mathrm{O}_{2}$ (see Figure 9). These results are unexpected, as differences in ionic conductivity should be accounted for by the $H F R$ and $R_{H^{+} \text {,cath }}^{\text {eff }}$ correction. Unfortunately, at this point we can only conclude that not all resistances are captured quantitatively by the here used $\mathrm{O}_{2}$ and $\mathrm{H}^{+}$transport resistance measurements and that further work is needed to understand the $R H$ dependence of these catalysts where $\mathrm{Pt}$ is located predominantly on the external carbon support surface. 


\section{Conclusions}

The effect of the synthesis method for the deposition of Pt nanoparticles on a high surface area Ketjenblack carbon support with respect to the ECSA, the ORR mass activity, and the fuel cell performance of the resulting catalysts was investigated. For catalysts prepared by a polyol synthesis method, strong evidence is supported that Pt particles were predominantly deposited on the external Ketjenblack support surface, as indicated by TEM images and by an analysis of the ORR activity. On the other hand, the same analysis suggested that catalysts prepared by an incipient wetness synthesis method as well as a commercial $\mathrm{Pt} / \mathrm{KB}$ catalyst are characterized by a predominant location of $\mathrm{Pt}$ particles within the carbon nanopores.

The catalysts prepared by the polyol reduction showed superior high current density performance, but their ORR mass activity was comparatively low. In contrast, the catalysts with Pt particles located predominantly in carbon nanopores showed a higher ORR mass activity but poor high current density performance due to mass transport limitations. This trend has commonly been observed when comparing Vulcan supported catalysts (behaving like our polyol synthesized catalysts) with Ketjenblack supported catalysts and was attributed to differences in $\mathrm{Pt}$ particle location. Here we have shown that the $\mathrm{Pt}$ particle location on a given carbon support can also be controlled by the synthesis method. Thus, by tailoring the synthetic method so that Pt particles were deposited predominantly on the external carbon surface, a catalyst with low oxygen mass transport resistance and good high current density performance can be obtained; for these polyol synthesis based catalysts supported on Ketjenblack (often referred to as porous carbon), the unaccounted losses in a voltage loss analysis were minimized and are similarly low as for catalysts based on a Vulcan carbon support (often referred to as solid carbon). When $\mathrm{Pt}$ is predominantly located inside the carbon pores, a lower $\mathrm{O}_{2}$ transport resistance, hence better performance at high current density is observed at $70 \%$ compared to $100 \% \mathrm{RH}$ (after correction of increased ionic resistances), which points toward an additional $\mathrm{O}_{2}$ transport resistance from (partially) water filled carbon pores at fully humidified conditions.

In summary, a catalyst should exhibit most Pt particles on the outer surface of the carbon black support to enable high current density operation with low mass transport related losses in addition to a small fraction of platinum particles shielded inside the pores from ionomer poisoning for high mass activity.

\section{Acknowledgments}

This work has been supported by Greenerity GmbH and the German Federal Ministry of Economy (BMWi project support number 03ET2058C) within the HyMotion5 research collaboration. We thank Matthias Binder, Christian Eickes, Peter Suchsland, and Jozsef Speder from Greenerity $\mathrm{GmbH}$ for their valuable and critical discussion of the here presented results.

\section{ORCID}

Gregor S. Harzer (D) https://orcid.org/0000-0002-1830-1931

\section{References}

1. J. Durst, A. Siebel, C. Simon, F. Hasche, J. Herranz, and H. A. Gasteiger, Energy Environ. Sci., 7, 2255 (2014).
2. O. Gröger, H. A. Gasteiger, and J.-P. Suchsland, J. Electrochem. Soc., 162, A2605 (2015).

3. A. Kongkanand and M. Mathias, J. Phys. Chem. Lett., 7, 1127 (2016).

4. B. Han, C. E. Carlton, A. Kongkanand, R. S. Kukreja, B. R. Theobald, L. Gan, R. O'Malley, P. Strasser, F. T. Wagner, and Y. Shao-Horn, Energy Environ. Sci., 8, 258 (2015).

5. C. Cui, L. Gan, H.-H. Li, S.-H. Yu, M. Heggen, and P. Strasser, Nano Lett., 12, 5885 (2012).

6. C. Chen, Y. Kang, Z. Huo, Z. Zhu, W. Huang, H. L. Xin, J. D. Snyder, D. Li, J. A. Herron, M. Mavrikakis, M. Chi, K. More, N. Markovic, G. Somorjai, P. Yang, and V. Stamenkovic, Science, 343, 1339 (2014).

7. C. Baldizzone, S. Mezzavilla, H. W. Carvalho, J. C. Meier, A. K. Schuppert, M. Heggen, C. Galeano, J.-D. Grunwaldt, F. Schüth, and K. J. Mayrhofer, Angew. Chem. Int. Ed., 53, 14250 (2014).

8. F. Van Schalkwyk, G. Pattrick, J. Olivier, O. Conrad, and S. Blair, Fuel Cells, 16, 414 (2016).

9. Y. Liu, C. Ji, W. Gu, J. Jorne, and H. A. Gasteiger, J. Electrochem. Soc., 158, B614 (2011).

10. M. Uchida, Y. Fukuoka, Y. Sugawara, N. Eda, and A. Ohta, J. Electrochem. Soc., 143, 2245 (1996).

11. A. Kongkanand, V. Yarlagadda, T. R. Garrick, T. E. Moylan, and W. Gu, ECS Trans., 75, 25 (2016)

12. V. Yarlagadda, M. K. Carpenter, T. E. Moylan, R. S. Kukreja, R. Koestner, W. Gu, L. Thompson, and A. Kongkanand, ACS Energy Letters, 3, 618 (2018).

13. Y.-C. Park, H. Tokiwa, K. Kakinuma, M. Watanabe, and M. Uchida, J. Power Sources, 315, 179 (2016)

14. H. Jinnai, R. Spontak, and T. Nishi, Macromolecules, 43, 1675 (2010).

15. A. Orfanidi, P. Madkikar, H. El-Sayed, G. S. Harzer, T. Kratky, and H. A. Gasteiger, J. Electrochem. Soc., 164, F418 (2017).

16. G. S. Harzer, J. N. Schwämmlein, A. M. Damjanović, S. Ghosh, and H. A. Gasteiger, J. Electrochem. Soc., 165, F3118 (2018).

17. C. Simon, F. Hasché, and H. A. Gasteiger, J. Electrochem. Soc., 164, F591 (2017).

18. C. Simon, F. Hasché, D. Müller, and H. A. Gasteiger, ECS Trans., 69, 1293 (2015).

19. S. Biniak, G. Szymański, J. Siedlewski, and A. Świątkowski, Carbon, 35, 1799 (1997).

20. J. Jaramillo, P. Álvarez, and V. Gómez-Serrano, Appl. Surf. Sci., 256, 5232 (2010).

21. B. Strehle, S. Solchenbach, M. Metzger, K. U. Schwenke, and H. A. Gasteiger, J. Electrochem. Soc., 164, A2513 (2017).

22. J. Speder, A. Zana, and M. Arenz, Catalysis today, 262, 82 (2016)

23. E. P. Ambrosio, C. Francia, C. Gerbaldi, N. Penazzi, P. Spinelli, M. Manzoli, and G. Ghiotti, J. Appl. Electrochem., 38, 1019 (2008).

24. C.-Y. Ahn, J.-Y. Cheon, S.-H. Joo, and J. Kim, J. Power Sources, 222, 477 (2013).

25. K. Shinozaki, Y. Morimoto, B. S. Pivovar, and S. S. Kocha, J. Power Sources, 325, 745 (2016).

26. P. Ferreira, G. J. la O', Y. Shao-Horn, D. Morgan, R. Makharia, S. Kocha, and H. A. Gasteiger, J. Electrochem. Soc., 152, A2256 (2005).

27. Y. Garsany, I. L. Singer, and K. E. Swider-Lyons, J. Electroanal. Chem., 662, 396 (2011).

28. M. Uchida, Y.-C. Park, K. Kakinuma, H. Yano, D. A. Tryk, T. Kamino, H. Uchida, and M. Watanabe, Phys. Chem. Chem. Phys., 15, 11236 (2013).

29. H. A. Gasteiger, S. S. Kocha, B. Sompalli, and F. T. Wagner, Appl. Catal., B, 56, 9 (2005).

30. H. Iden and A. Ohma, J. Electroanal. Chem., 693, 34 (2013).

31. A. Ohma, T. Mashio, K. Sato, H. Iden, Y. Ono, K. Sakai, K. Akizuki, S. Takaichi, and K. Shinohara, Electrochim. Acta, 56, 10832 (2011).

32. T. R. Garrick, T. E. Moylan, V. Yarlagadda, and A. Kongkanand, J. Electrochem. Soc., 164, F60 (2017).

33. F. Yang, L. Xin, A. Uzunoglu, Y. Qiu, L. Stanciu, J. Ilavsky, W. Li, and J. Xie, ACS Appl. Mater. Interfaces, 9, 6530 (2017).

34. L. Xin, F. Yang, S. Rasouli, Y. Qiu, Z.-F. Li, A. Uzunoglu, C.-J. Sun, Y. Liu, P. Ferreira, W. Li, Y. Ren, L. Stanciu, and J. Xie, ACS Catalysis, 6, 2642 (2016).

35. K. Neyerlin, W. Gu, J. Jorne, and H. A. Gasteiger, J. Electrochem. Soc., 153, A1955 (2006).

36. D. R. Baker, D. A. Caulk, K. C. Neyerlin, and M. W. Murphy, J. Electrochem. Soc., 156, B991 (2009)

37. J. P. Owejan, J. E. Owejan, and W. Gu, J. Electrochem. Soc., 160, F824 (2013).

38. H. Oh, Y. il Lee, G. Lee, K. Min, and S. Y. Jung, J. Power Sources, 345, 67 (2017)

39. N. Subramanian, T. Greszler, J. Zhang, W. Gu, and R. Makharia, J. Electrochem. Soc., 159, B531 (2012)

40. C. Mittelsteadt and H. Liu, in Handbook of Fuel Cells, $1^{\text {st }}$ ed., W. Vielstich, A. Lamm, and H. A. Gasteiger, vol 5, p. 348, John Wiley \& Sons Ltd, Chichester (2009).

41. Y. Liu, M. W. Murphy, D. R. Baker, W. Gu, C. Ji, J. Jorne, and H. A. Gasteiger, J. Electrochem. Soc., 156, B970 (2009). 